\title{
The Shift to Strict VO in English at the PF-Interface*
}

\author{
Agnieszka Pysz \\ agape@hivolda.no \\ Høgskulen i Volda
}

\author{
Bartosz Wiland \\ bartek@ifa.amu.edu.pl \\ University of Poznań
}

First draft: November 2008

Revised: December 2009

This paper proposes a novel analysis of the shift to the strict VO word order in the history of English. We begin with pointing out that the previous accounts of this shift are problematic at least for two reasons. First, they do not explain why at some point in its history English became a strict word order language, nor why it became strict VO rather than strict OV. Second, they do not capture a number of diachronic and cross-linguistic facts. We provide a principled account of the shift to the strict VO under which these facts fall into place. We argue that the setting of strict VO in English was necessitated by the loss of m(orphological)-case on nominals. This follows from a theory in which the presence of zero case exponents requires local licensing at the PF interface.

\section{Introduction}

The idea that the morphological richness of nominal inflection has or may have effects on word order is not new. It was explored under various guises in many traditional studies, resulting in different judgments as to the validity of this idea. More specifically, among the scholars who subscribe to the view that there is some relation between impoverished inflection and rigid word order, two positions are taken. On the one hand, Lehnert (1957) and Trnka (1928) take the position that it is the fixation of word order that makes the loss of inflection on nominals possible, though not necessarily required. On the other hand, Marchand (1951) and Sapir (1921) support the thesis that it is the loss of nominal inflection that leads to the fixation of word order. On the basis of the diachronic facts from English, we support the latter position and argue that the fixation of $\mathrm{VO}$ is a consequence of the loss of overt case marking on nominals. This clearly counters a common view defended by generativists dealing with the history of English syntax (e.g. Kiparsky 1996, McFadden 2004, Pintzuk 1999, 2002), according to which the developments in $\mathrm{OV} / \mathrm{VO}$ are not related to nominal morphology. A reinterpretation of the well-known OV/VO data leads us, however, to a strikingly different conclusion.

The paper is organized as follows. Section 2 presents the basic facts concerning the change to strict VO in the history of English and reconsiders a hotly debated issue of whether this change had to do with the loss of m-case on English nominals. Section 3 reviews a selection of analyses that were proposed to handle the shift from OV to strict VO. We conclude that the

\footnotetext{
* Many thanks to audiences at the University of Arizona, Lund University, University of Poznań and CASTL/University of Troms $\emptyset$, where earlier versions of this work were presented. We especially thank Piotr Cegłowski, David Pesetsky, Gillian Ramchand, Michal Starke, Peter Svenonius, and Jacek Witkoś for suggestions and comments on aspects of this work. We also thank the reviewers and the editors of this volume for excellent comments. All errors are our own responsibility.
} 
previous analyses are unsatisfactory insofar as they fail to address the fundamental question of why English actually developed strict VO. In sections 4 and 5 we develop an alternative account of OV/VO in English, based on the idea that the licensing locality of null morphemes can be defined post-syntactically, at the PF interface. We show that the account finds solid support in cross-linguistic facts. We then show that the account based on the PF locality makes correct predictions beyond OV/VO. Section 6 considers three problems with our proposal, which we show to be apparent. Section 7 is a conclusion.

\section{Basic facts}

This section presents the basic facts about the shift to strict VO in the history of English. Our aim is to give a general picture of the change in question and relate it chronologically to the reductions which affected the inflectional endings of English nominals over a few centuries. We do not aim to delve into any details regarding the frequencies of OV and VO orders in respective periods of English nor do we aim to discuss the motivations behind the choice between $\mathrm{OV}$ and $\mathrm{VO}$ in periods when both orders were attested. ${ }^{1}$

\subsection{From mixed $0 V / V O$ to strict VO}

In what follows we briefly present the basic diachronic facts concerning the change whereby English became a strict VO language. The relevant facts are as follows.

In the Old English period, i.e. between $449 \mathrm{AD}$ and $1066 \mathrm{AD}$, both $\mathrm{OV}$ and VO surface orders could be found. This is illustrated in (1)-(5), in which the finite verb, the non-finite verb, and its object occur in embedded clauses. ${ }^{2}$ Examples (1) and (2) illustrate surface OV, where the non-finite verb follows the object. In (1), the finite verb follows the OV cluster, while in (2) it precedes the OV cluster.

- Obj-V-Aux:

(1) gif hie ænigne feld secan wolden

if they any field seek wanted

'if they wanted to seek out an open field' (van Kemenade 1987:196)

- Aux-Obj-V:

(2) pæt he mehte his feorh generian that he could his property save

'that he could save his property' (Fuss \& Trips 2002:176)

(3) illustrates a surface VO, where the non-finite verb precedes its object and the finite verb precedes the VO cluster.

- Aux-V-Obj:

(3) pæt he mot ehtan godra manna

that he might persecute good men

'that he might persecute good men' (Biberauer \& Roberts 2005, (21))

The existence of the order in which the finite verb follows the VO cluster, i.e. V-Obj-Aux, is 
dubious. This word order is usually considered non-existent or (at least) rarely attested, both in $\mathrm{OE}$ and cross-linguistically. ${ }^{3}$

Examples (4) and (5) illustrate surface patterns in which the sequence of the non-finite verb and the object is split by the finite verb. In (4), the finite verb splits the OV sequence, and in (5) the finite verb splits the VO sequence.

- Obj-Aux-V:

(4) pæt he Saul ne dorste ofslean that he Saul NEG dared murder 'that he did not dare to murder Saul' (Fuss \& Trips 2002:175)

- V-Aux-Obj:

(5) pæt ænig mon atellan mæge ealne pone demm that any man relate can all the misery 'that any man can relate all the misery' (Fuss \& Trips 2002:175)

For the sake of exposition, the five surface orders illustrated in (1)-(5) are summarized in (6ae).

(6) Major OV/VO surface orders attested in OE
a. Obj-V-Aux
b. Aux-Obj-V
c. Aux-V-Obj
d. Obj-Aux-V
e. V-Aux-Obj

In the remainder of the paper, we restrict ourselves to the three surface patterns corresponding to (6a-c), thus leaving aside the two patterns that instantiate (6d-e). We focus on patterns with nominal objects, thus disregarding those in which objects are pronominal (there is considerable consensus in the literature that the distributional properties of pronouns differ from the distributional properties of nouns, see for instance Cardinaletti \& Starke 1999; for OE see van Kemenade 1984, Koopman 1992,1997). Within nominal objects, we do not deal with negative and quantified objects as their behavior differs from that of positive objects (to give one example, negative objects in $\mathrm{OE}$ are regularly absent in the pattern corresponding to V-Aux-Obj; see Pintzuk 2005). Finally, we restrict ourselves to patterns with one object, thus disregarding the so-called double object constructions (see Koopman 1990, 1991-1993). The exclusion of the above contexts from the discussion does not affect the gist of our argument.

As the patterns in (6) indicate, OE sentences were characterized by a considerable freedom of word order. This freedom was subsequently restricted, as a result of which English developed a strict word order, specifically, strict VO. There is a considerable consensus among scholars as regards the approximate date in which this change happened. A few statements representative of the general view are adduced below.

According to Moerenhout \& van der Wurff (2000:513), the shift to VO took place in the $12^{\text {th }}$ century, i.e. in early ME, a period immediately postdating OE. This is consonant with van Kemenade's (1987:174-175) statement that the fixation of VO 'must be assumed to have been completed by $1200 '$. McFadden $(2004, \S 5.2 .2)$ ventures to claim that the beginnings of VO can 
be traced back to as early as the middle of the $10^{\text {th }}$ century. Yet, in our opinion, the very fact that surface VO orders were attested at such an early stage should not be taken to mean that the shift to strict VO was already under way then. As will become evident from our discussion in further sections, the co-occurrence of surface $\mathrm{OV}$ and VO is fully expected at a stage in which a given language has sufficiently robust $\mathrm{m}$-case on nominals. It is only when $\mathrm{m}$-case is lost or considerably reduced that certain restrictions on word order begin to hold. Abstracting away from the details, we may generalize that in the history of English the shift to strict VO took place during the $12^{\text {th }}$ century. Similar generalizations may be found, e.g. in Kiparsky (1996) and Roberts (1997:397). 4

A remark concerning one particular aspect of the shift to VO in English is in place here. We base the analysis on the premise that OE had a mixed OV/VO order rather than strict OV. Taking this to be the case, we disagree with fairly common claims that English underwent a shift (gradual or abrupt) from a stage in which OV was the predominant order to a stage in which VO became predominant (see, e.g. Kiparsky 1996). Instead, we argue that shift should adequately be analyzed as the elimination of OV leading to the fixation of VO. Crucially, our view is not incompatible with word order facts from the pre-OE times, whether from ProtoIndo-European (PIE) or Proto-Germanic (PGmc). Although in many studies PIE and PGmc are claimed to be OV languages (for PIE see Wackernagel 1892; for PGmc see Smith 1971), there is much to commend the view that they are best treated as languages with free word order (see for instance Grace 1971 and Kuhn 1933). ${ }^{5}$

\subsection{The fixation of strict $V O$ and the loss of morphological case: Independent changes?}

There is some disagreement in the literature whether the shift to strict VO in English had anything to do with the loss of m-case.

According to van Kemenade (1987:202), the reductions in the English nominal inflection took place mainly during the $11^{\text {th }}$ and $12^{\text {th }}$ centuries. Her opinion agrees with Roberts's (1997:421) claim that the OE m-case system broke down in the early ME period, i.e. precisely in the two centuries following 1066 AD. McFadden (2005) observes that the English case system distinguishing four cases, i.e. Nom, Gen, Dat, Acc, was still intact at the end of the $11^{\text {th }}$ century and that it reduced to its current complexity by the middle of the $13^{\text {th }}$ century. Again, details aside, it can be generalized that the change whereby English nominals lost overt inflectional marking operated between the $11^{\text {th }}$ century and the mid $13^{\text {th }}$ century (see Allen 1995).

The above statements lead to the conclusion that the fixation of strict VO and the loss of $\mathrm{m}$-case in English proceeded more or less in parallel. Obviously, the mere chronological overlap between the two changes is no evidence that they were syntactically related to each other. A great number of scholars actually subscribe to the opposite view.

Kiparsky (1996) and McFadden (2005), for instance, claim that the establishment of VO in English progressed independently of the changes in the nominal morphology. 6 The main piece of evidence on which they base this claim is the fact that English allowed VO surface orders well before it lost m-case on nominals. Thus, Kiparsky (1996) maintains that the shift to strict VO began in OE before the collapse of the m-case system (specifically, he mentions late $\mathrm{OE}$, which was well on its way to strict VO, yet retained m-case distinctions between Nom and Acc). In a similar vein, McFadden (2005) states that the rate of surface VO orders was already high in the period when the case system was at its robust. He adds one more argument in support of his standpoint, namely that the replacement of OV by VO did not occur suddenly after the collapse of m-case. This leads him to conclude that the two changes must be independent (note that McFadden treats the shift to strict VO in terms of the replacement of OV 
by VO).

Kiparsky's (1996) and McFadden's (2005) proposals are based on fairly well-known empirical facts. We use the same empirical facts but we argue for a radically different view, namely that the fixation of $\mathrm{VO}$ in English cannot be considered in isolation from the changes in the nominal morphology. Following Neeleman \& Weerman (1999), we defend the view that the presence of m-case by no means excludes the existence of VO orders. Rather, the presence of $\mathrm{m}$-case makes it possible for a language to have both $\mathrm{OV}$ and VO. ${ }^{7}$ Given this, it comes as no surprise that the surface VO orders were attested at a stage when English nominals were marked for m-case. Thus, the occurrence of such orders does not mean, as Kiparsky (1996) and McFadden (2005) maintain, that the shift to VO was in progress at this stage.

In what follows, we argue that the shift to VO could begin only when nominals came to be affected by inflectional reductions. As m-case was gradually obliterated and eventually lost, so were surface OV orders. A technical implementation of this proposal is spelled out in section 4 .

\section{Previous accounts of the shift to strict VO in English}

This section presents selected generative analyses that were proposed to deal with the shift to strict VO in the history of English. Rather than providing a comprehensive review of the previous research in this area, the section aims to give a general picture of the most representative analyses of the change in question.

The accounts can be divided into three groups, depending on the theoretical assumptions on which they are based: the Head Complement Parameter, the Universal Base Hypothesis, and the Double Base Hypothesis. We next pinpoint one general, albeit very serious, defect from which all these analyses suffer.

\section{1. $H\left(\right.$ ead) C(omplement) $P\left(\right.$ arameter)-based account ${ }^{8}$}

The focus of this section is on a classical account of OV/VO in English by van Kemenade (1987), who relies on the Head Complement Parameter. The account reported here is a revamped version of van Kemenade's (1987) original proposal (we introduce a few cosmetic changes to make it fit in with more recent assumptions about the clausal structure). According to the generalized HCP-based account, OE is treated as a language with a head-final VP, a head-final IP and a head-initial CP. This is reminiscent of the classical analyses proposed in the context of contemporary West-Germanic languages, notably Modern Dutch (e.g. Koster 1975) and Modern German (e.g. Thiersch 1978). Let us see how van Kemenade (1987) deals with the derivation of the three surface orders (6a-c).

The pattern Obj-V-Aux is obtained in a straightforward way insofar as it does not require any movements. Assuming that the non-finite verb sits in the head of VP, while the finite verb is base-generated in the head of IP, yields the structure in (7). ${ }^{9}$

(7) [IP [vP Obj V] Aux ]

To deal with the two remaining patterns, i.e. Aux-Obj-V and Aux-V-Obj, van Kemenade (1987) resorts to rightward movements. The derivation of Aux-Obj-V involves Verb Projection Raising, whereby the whole VP right-moves and right-adjoins to the IP. This is shown in (8).

(8) $\quad\left[\right.$ IP $\left[\right.$ IP $t_{i}$ Aux $\left.]\left[\mathrm{vP}_{\mathrm{O}} \mathrm{Obj} \mathrm{V}\right]_{\mathrm{i}}\right]$ 
The pattern Aux-V-Obj is derived in two steps. The first step involves Verb Raising (see Evers 1975, Rutten 1991 in the context of Dutch), whereby the non-finite verb right-moves and rightadjoins to the head of the IP, as in (9a). The next step consists in Object Extraposition, as in (9b).
(9) a. [IP [vP Obj t $\left.\left.t_{i}\right] \mathrm{Aux}+\mathrm{V}_{\mathrm{i}}\right]$
b. [IP [IP [vP $\left.\left.\left.t_{j} t_{i}\right] A u x+V_{i}\right] O b j_{j}\right]$

All in all, according to van Kemenade's (1987) analysis, the shift to VO is viewed in terms of the change in the setting of the head-parameter at the VP level. That is, English is viewed as having undergone the change from a language with a head-final VP to a language with a head-initial VP. As van Kemenade (1987) suggests, the change in question was motivated by an increase in the frequency of surface VO orders, notably those corresponding to (9). What presumably happened is that in the course of time language acquirers started to reanalyze these derived VO orders as base VO orders. As a result of this reanalysis, a head-initial VP became the default setting.

\section{2. $U$ (niversal) $B($ ase $) H($ ypothesis)-based accounts}

This section gives a synopsis of the accounts employing Kayne's (1994) Universal Base Hypothesis and assuming that $\mathrm{OE}$, like all languages, is underlyingly VO. The Kaynean version of UBH should be distinguished from that by Haider (2000), according to which OV constitutes the Universal Base, from which VO is subsequently derived. Below, we concentrate on two UBH-based accounts, i.e. Roberts (1997) and Biberauer \& Roberts $(2005,2006)$ (henceforth, B\&R). Other proposals in a similar spirit include, e.g. van der Wurff (1999).

Let us start with Roberts (1997), whose original proposal is simplified here for expository purposes (he inter alia postulates as many as ten positions in the structure of OE clauses; see Roberts 1997:415). Under his account, surface OV orders observed in OE result from leftward object movement targeting Spec-AgrOP (Chomsky 1995), as in (10).

$$
\left[\mathrm{AgrOP} O \mathrm{Obj}_{\mathrm{i}}\left[\mathrm{vP} \mathrm{V} \mathrm{t}_{\mathrm{i}}\right]\right]
$$

Under Roberts's (1997) assumptions, the movement of the object is motivated by the need to check case on the nominal. The features triggering movement sit on the head of the AgrOP and their strength is determined by the presence/absence of $\mathrm{m}$-case on nominals. If nominals are $\mathrm{m}$-case marked, the features on $\mathrm{AgrO}^{0}$ are strong and object movement is overt. Otherwise, the features are weak and object movement is covert. Given that OE nominals were marked for mcase (even though not all nominals had overt inflection in all cases), the object movement took place in the overt component, hence the surface OV. Let us see how the three orders corresponding to (6a-c) are obtained via such a proposal.

The pattern Obj-V-Aux is obtained in two steps. First, Obj moves to Spec-AgrOP, as in (11a). Then, the remnant AgrOP moves to Spec-AuxP, as in (11b).
a. [Auxp Aux [YP [AgrOP $\left.\left.\left.\mathrm{Obj}_{\mathrm{i}}\left[\mathrm{vP} \mathrm{V} \mathrm{t}_{\mathrm{i}}\right]\right]\right]\right]$
b. [AuxP [Agrop Obj ${ }_{i}\left[\mathrm{vP} V t_{i}\right]_{j}$ Aux [YP $\left.\left.\left.t_{j}\right]\right]\right]$

The derivation of Aux-Obj-V involves only one movement, whereby Obj is raised to Spec-AgrOP, as in (12). 
Finally, the pattern Aux-V-Obj has two alternative derivations (for a critique of both see McFadden 2005). One scenario involves no movements, as in (13), and applies only if a given object is focused. Roberts (1997) posits that focused objects remain in situ because focus exempts them from the requirements of the Case Theory.

$$
\text { [Auxp Aux [yP [AgrOP [ve V Obj ]]]] }
$$

The alternative derivation of Aux-V-Obj, applicable to non-focused objects, is shown in (14). Here, three movements are involved, i.e. Obj to Spec-AgrOP, as in (14a), V to the head of AuxP with left-adjunction to Aux, as in (14b), and movement of Aux across V to the head of some higher XP, as in (14c).

(14) a. [AuxP Aux [yP [AgrOP Obji [vp $\left.\left.\left.\left.V t_{i}\right]\right]\right]\right]$

b. [AuxP $V_{j}+$ Aux [YP [AgrOP Obji $\left.\left.\left.\left[v p t_{j} t_{i}\right]\right]\right]\right]$

c. $\left[\operatorname{Xp}^{A u x_{k}}\left[\operatorname{AuxP}_{j}+t_{k}\left[\mathrm{YP}\left[\operatorname{AgrOP} O b j_{i}\left[v p t_{j} t_{i}\right]\right]\right]\right]\right]$

Pared down to essentials, Roberts's (1997) scenario treats the shift to strict VO as a change in the strength of the features responsible for object movement. When the morphological evidence in the form of overt inflection on nominals was lost, the movement-triggering features on $\mathrm{AgrO}^{0}$ changed from strong to weak (we abstract away here from Roberts's claim that the presence of strong features may also be postulated on the basis of syntactic evidence).

Consider now the gist of B\&R's (2005) UBH-based account. Central to this proposal is the presence of a movement diacritic, the EPP-feature (see Chomsky 2000, 2001, 2004), which occupies two clausal functional heads, i.e. $\mathrm{v}^{0}$ and $\mathrm{T}^{0}$. They argue that in $\mathrm{OE}$ both $\mathrm{v}^{0} \mathrm{~s}$ and $\mathrm{T}^{0} \mathrm{~s}$ EPP could be satisfied in one of the two ways. ${ }^{10}$ One possibility was by DP movement of a nonpied-piping (or stranding) type, and the other by 'large XP' movement of a pied-pipingtype. Thus, EPP on $v^{0}$ could be satisfied by moving to SpecvP either the object alone, as in (15a), or by moving the VP containing the object, as in (15b).

(15) a. [vP Objj $\left.\mathrm{V}_{\mathrm{i}}\left[\mathrm{vp} \mathrm{t}_{\mathrm{i}} \mathrm{t}_{\mathrm{j}}\right]\right]$

b. [vP $\left.\left[\mathrm{vP}_{\mathrm{i}} \mathrm{Obj}\right]_{j} \mathrm{~V}_{\mathrm{i}} \mathrm{t}_{\mathrm{j}}\right]$

A similar scenario is postulated for EPP on $\mathrm{T}^{0}$. That is, it could also be satisfied by moving to Spec-TP either the subject alone, as in (16a), or by moving the vP containing the subject, as in (16b).

(16) a. [TP $\operatorname{Subj}_{\mathrm{k}} \mathrm{T}\left[\mathrm{vp}_{\mathrm{k}} \mathrm{t}_{\mathrm{k}} \mathrm{Obj}_{\mathrm{j}} \mathrm{V}_{\mathrm{i}}\left[\mathrm{vP} \mathrm{t}_{\mathrm{i}} \mathrm{t}_{\mathrm{j}}\right]\right]$

b. [тр [vp Subj Obj $\left.\left.\mathrm{V}_{\mathrm{i}}\right]_{\mathrm{k}} \mathrm{T} \mathrm{t}_{\mathrm{k}}\left[\mathrm{vp} \mathrm{t}_{\mathrm{i}} \mathrm{t}_{\mathrm{j}}\right]\right]$

Here is how B\&R's $(2005,2006)$ system deals with the three relevant surface orders. The pattern Obj-V-Aux is derived by three movements, namely $\mathrm{V}^{0}$-to- $\mathrm{V}^{0}$, as in (17a), VP to inner Spec-vP, as in (17b), and vP to Spec-TP, as in (17e). Thus, both $\mathrm{v}^{0}$ 's EPP and $\mathrm{T}^{0}$ 's EPP are satisfied by the pied-piping movement. On the way, Subj is merged in outer Spec-vP, as in (17c), and Aux is merged in $\mathrm{T}^{0}$, as in $(17 \mathrm{~d})$. 
(17) a. [vP $V_{i}\left[v p t_{i}\right.$ Obj ]]

b. $\left[\mathrm{vP}\left[\mathrm{vP} t_{\mathrm{i}} \mathrm{Obj}\right]_{\mathrm{j}} \mathrm{V}_{\mathrm{i}} \mathrm{t}_{\mathrm{j}}\right]$

c. [vP Subj [vP [vp $\left.\left.\left.t_{i} O b j\right]_{j} V_{i} t_{j}\right]\right]$

d. [тр Aux [vp Subj [vp [vp $\left.\left.\left.\left.t_{i} O b j\right]_{j} V_{i} t_{j}\right]\right]\right]$

e. [тр [vp Subj [vp [vp $\left.\left.\left.\left.t_{i} O b j\right]_{j} V_{i} t_{j}\right]\right]_{k} A u x t_{k}\right]$

Three movements are also employed to obtain the pattern Aux-Obj-V, namely $\mathrm{V}^{0}$-to- $\mathrm{V}^{0}$, as in (18a), VP to inner Spec-vP, as in (18b), and Subj to Spec-TP (18e). In this case, $v^{0}$ 's EPP is satisfied by the pied-piping movement, while $\mathrm{T}^{0} \mathrm{~s}$ EPP by the non-pied-piping variant. Two merges take place en route, i.e. Subj is merged in outer Spec-vP, as in (18c), and Aux is merged in $\mathrm{T}^{0}$, as in (18d).

(18) a. [vP $\left.V_{i}\left[v p t_{i} O b j\right]\right]$

b. [vP [vp $\left.\left.t_{i} O b j\right]_{j} V_{i} t_{j}\right]$

c. [vp Subj [vp [vp $\left.\left.\left.t_{i} O b j\right]_{j} V_{i} t_{j}\right]\right]$

d. [Tr Aux [vp Subj [vp [vp $t_{i}$ Obj ]j $\left.\left.\left.V_{i} t_{j}\right]\right]\right]$

e. [TP Subjk $j_{k}$ Aux [vp $\left.\left.t_{k}\left[{ }_{v P}\left[v p t_{i} O b j\right]_{j} V_{i} t_{j}\right]\right]\right]$

The derivation of Aux-V-Obj involves two movements. First, $\mathrm{V}^{0}$ moves to $\mathrm{v}^{0}$, as in $19 \mathrm{a}$, and then Subj moves to Spec-TP, as in $19 \mathrm{~d}$. Here, whereas $\mathrm{T}^{0} \mathrm{~s}$ EPP is satisfied by the non-pied-piping movement, $\mathrm{v}^{0} \mathrm{~s}$ EPP is assumed to be absent (for some motivation behind the claim that the presence of EPP on $v^{0}$ in OE was optional see B\&R 2005:19ff.). As previously, in-between merges involve the merging of Subj in outer Spec-vP, as in (19b), and the merging of Aux in $\mathrm{T}^{0}$, as in (19c).

(19) a. [vP $V_{i}\left[v p t_{i}\right.$ Obj ]]

b. [vp Subj [vP $V_{i}\left[v p t_{i}\right.$ Obj ]]]

c. [тр Aux [vp Subj [vP $V_{i}\left[\mathrm{vp}_{\mathrm{i}} \mathrm{Obj}\right.$ ]]]]

d. [тр Subj $j_{j}$ Aux [vp t $\left.\left.{ }_{j}\left[\mathrm{vP}_{\mathrm{i}}\left[\mathrm{vP} \mathrm{t}_{\mathrm{i}} \mathrm{Obj}\right]\right]\right]\right]$

It may be generalized that the shift to VO in English, as viewed by B\&R's (2005) proposal, consisted in eliminating the possibility of satisfying EPP by pied-piping. English, thus, underwent a change from a language in which EPP could be satisfied in two ways to a language in which EPP could by satisfied only by the non-pied-piping movement. Significantly, it seems that such a scenario rests on the assumption that English must have lost EPP on $v^{0}$, hence object movement, in the course of its history.

\section{3. $\mathrm{D}$ (ouble) $\mathrm{B}$ (ase) $\mathrm{H}$ (ypothesis)-based accounts}

This section focuses on the accounts employing the Double Base Hypothesis (Kroch 1989), whereby OE is treated as OV and VO at the same time. We concentrate on two DBH-based analyses, i.e. Pintzuk (1991) and Fuss \& Trips (2002). They are both inspired by the idea, first adopted in Santorini's $(1989,1992,1993)$ studies of historical changes in Yiddish, that a speaker can have more than one grammar. For some time the co-existing grammars compete with each other (Grammar Competition, Kroch 1989). Gradually, one of these competing grammars gains the upper hand and wins out. ${ }^{11}$

According to Pintzuk (1991) (see also Kroch \& Taylor 1997, 2000), 12 OE allowed for the co-existence of three grammatical systems. These three systems stand behind the variation in 
the surface order found in the OE data, including the three patterns with which we are concerned here. In Pintzuk's proposal, the pattern Obj-V-Aux may be obtained from the grammar with a head-final VP and a head-final IP. This is shown in (20), assuming a stringvacuous movement from the head of a higher VP to the head of the IP.

(20) [IP [vp [vP Obj V ] t $\left.\left.\mathrm{v}_{\mathrm{i}}\right] \mathrm{Aux}_{\mathrm{i}}\right]$

The pattern Aux-Obj-V may be handled by a grammar with a head-final VP and a head-initial IP, as in (21).

(21) [IP Auxi [vp [vp Obj V ] t $\left.t_{i}\right]$

Finally, the pattern Aux-V-Obj is derivable from a head-initial VP and a head-initial IP, as in (22).

(22) [IP Auxi $\left[\mathrm{vp}_{\mathrm{i}}[\mathrm{vP} \mathrm{V}\right.$ Obj ]]]

Under Pintzuk's (1991) story, the shift to strict VO consists in the establishment of a uniformly head-initial grammar, corresponding to (22), at the cost of two grammars with a head-final VP, corresponding to (20) and (21).

A somewhat later proposal employing the idea of the Double Base is due to Fuss \& Trips (2002). ${ }^{13}$ Like Pintzuk (1991), their account relies on the existence of three grammars, two of which have a head-final VP, while one is uniformly head-initial. Unlike Pintzuk (1991), Fuss \& Trips (2002) subscribe to the view that functional categories are universally head-initial (see Haider 1993, 2000). This allows them to preclude the generation of the non-existent order V-Obj-Aux: given that VP dominating VP cannot be head-final, the grammar with a head-initial VP and a head-final vP is thus excluded.

The orders (6a-c) are derived in the following way. The pattern Obj-V-Aux is derived from an OV-grammar without $\mathrm{vP}$, i.e. without $\mathrm{V}^{0}-$ to- $^{0}$ movement, as in (23). ${ }^{14}$

(23) [vp [v' [vp Obj V] Aux ]]

The pattern Aux-Obj- $\mathrm{V}$ is derived from an OV-grammar with vP, i.e. with $\mathrm{V}^{0}$-to- $\mathrm{v}^{0}$ movement, as in (24).

(24) $\left[\mathrm{vP}\left[\mathrm{v}^{\prime}\right.\right.$ Auxi $\left[\mathrm{vp}\left[\mathrm{v}^{\prime}[\mathrm{vp}\right.\right.$ Obj V $\left.\left.\left.\left.] \mathrm{t}_{\mathrm{i}}\right]\right]\right]\right]$

The pattern Aux-V-Obj is derived from a VO-grammar with vP, i.e. with $\mathrm{V}^{0}$-to- $\mathrm{v}^{0}$ movement, as in (25).

(25) [vp [v' Auxi $\left[v p\left[v^{\prime} t_{i}[v p\right.\right.$ V Obj ]]]]]

All in all, under Fuss \& Trips's (2002) proposal the shift to strict VO boils down to eliminating two OV-grammars, corresponding to (23) and (24), in favor of a uniformly head-initial grammar, corresponding to (25). 


\subsection{Challenges to the previous accounts}

Although the accounts reviewed in sections 3.1-3.3 offer a number of interesting insights, it appears that the work on the OV/VO phenomena calls for reconsideration. For reasons of space, we do not provide a detailed critique of each analysis separately. We will, thus, disregard some specific problems created by the respective proposals. Suffice it to name just a few of them, e.g. van Kemenade's (1987) extraposition applying to non-heavy elements such as pronouns, which is not found elsewhere in West-Germanic, or Roberts's (1997) overt syntactic movement being prompted by morphological marking. Instead, we focus on one serious flaw which all these analyses share, namely they do not explain why at some point in its history English became a strict word order language, nor do they explain why the English word order was fixed as a strict VO rather than strict OV. The previous accounts do not ignore these questions completely; nevertheless, the answers they provide are not sufficiently explanatory. Certain accounts, e.g. those based on HCP and UBH, postulate that the shift to strict VO was motivated by considerations of economy, specifically that strict VO was chosen as the more economical option (see the discussion below). If so, it remains a mystery why earlier periods of English were indifferent to such notions of economy and why the freedom of word order could not be maintained for longer. We briefly consider how this general problem manifests itself in the three groups of accounts reviewed in sections 3.1-3.3.

In van Kemenade's (1987) HCP-based account, the claim that the change from a headfinal VP to a head-initial VP happened as a result of reanalyzing derived VO as base VO raises a natural question about the reason for an increase in surface VO orders in the first place. That is, even if van Kemenade (1987) is right in claiming that such a reanalysis is defendable on the grounds of economy (overt movements entail bigger costs and are thus uneconomical), there remains a question of why at some point surface VO orders started to be used more frequently.

In the UBH-based accounts, the following problems arise. Both Roberts (1997) and B\&R $(2005,2006)$ treat the shift to VO in terms of the reduction in the number of movements. Thus, Roberts (1997) views the shift as a change from a stage in which English employed overt object movement to a stage in which overt object movement fell out of use. B\&R $(2005,2006)$, in turn, postulate that the shift involved a change from a stage in which two ways of satisfying EPP were available (i.e. pied-piping and stranding) to a stage in which only one possibility could be used (i.e. stranding). Again, both scenarios appeal to an economy factor. Roberts (1997) argues that weak features, hence the absence of overt object movement, are the default value and they are assumed if there is no morphological or syntactic evidence to the contrary. 15 B\&R (2005, 2006) refer to Clark \& Roberts (1993) and Roberts \& Roussou (2003), who claim that languages have an inbuilt preference for relatively simple structures. On such a view, the elimination of the pied-piping option reflects this preference for simplicity: since the stranding option involves the movement of less material than the pied-piping variant, the former is simpler and thus preferred (for a more detailed discussion see B\&R 2005:21ff., 43ff.). It is unclear, however, why this general preference for simplicity was not operative in OE and why it started to be respected only later. Neither Roberts (1997) nor B\&R (2005) give a viable answer.

A good deal of arguments against approaches employing movements may also be found in Pintzuk (2005) and, especially, Bouchard (2002). Of particular importance is the conceptual issue of motivating movement triggers, made explicit in Bouchard (2002:189): 
Concerning specific questions such as why is $X$ in position $P$, movement theory answers: because it moved there. The effort of explanation then shifts to the question why $\mathrm{X}$ moved to $\mathrm{P}$. The answer is an attempt to motivate movement, such as saying that the tool deriving it is free. The attempt to answer the original question why is $X$ in position $P$ is trivialized, becomes a secondary question of implementation: $\mathrm{X}$ is in $\mathrm{P}$ because a feature or category attracts $\mathrm{X}$ in $\mathrm{P}$.

When it comes to the DBH-based accounts, they are not fully satisfactory either. Although they offer an empirically adequate treatment of the synchronic variation observed in the OE word order, they nevertheless fare worse in explaining the development of word order over time. Crucially, both Pintzuk's (1991) and Fuss \& Trips's (2002) accounts rely on the existence of Blocking Effects (Aronoff 1976), which are imposed by Universal Grammar and which restrict the coexistence of minimally different systems. Given that the three competing grammars postulated in both accounts are minimally different, two of these grammars are predicted to be lost. Neither Pintzuk (1991) nor Fuss \& Trips (2002), however, provide a precise mechanism on the basis of which such a prediction may be implemented. Without such a mechanism, the task of determining which grammars turn out to be losers and which grammar turns out to be a winner becomes a matter of flipping the coin.

\section{Alternative: the PF locality condition on the insertion of null morphemes}

In what follows, we propose an alternative account of the shift to strict OV in English. We first review the "Government and PF-case checking" approach (henceforth G\&PF) to word order developed in the works by Neeleman \& Weerman (1999), Neeleman \& Reinhart (1998), and Neeleman (2002). Despite the fact that the G\&PF approach avoids many problems characteristic of the movement accounts of strict word order and has a potential for explaining the shift to strict VO in the history of English, we find one of its central theoretical claims, namely that case checking or assignment takes place post-syntactically at PF, problematic. We outline the G\&PF approach pointing out where it makes the wrong prediction about the order of operations in syntax. We then propose a modification and extension of G\&PF. The theory we develop assumes the existence of functional morphemes whose phonetic exponents can be zero and that lexical insertion comes after syntax. We then show that the change to strict VO in the history of English must be linked to the appearance of zero case exponents on nominal objects and is an immediate consequence of the modified G\&PF.

\subsection{The G\&PF approach to strict $O V / V O$}

Following Lamontagne \& Travis (1987) and Bittner \& Hale (1996), G\&PF assumes DPs to be universally equipped with the Case Phrase (KP) in their extended projection. In languages in which nominals have morphologically realized case markers, $\mathrm{K}^{0}$ is filled with a case affix, as in (26a), while in languages which lack $\mathrm{m}$-case $\mathrm{K}^{0}$ is an empty head, as in (26b).

a. m-case marked DPs

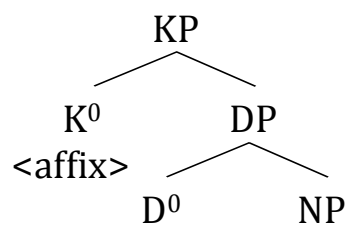

b. $\varnothing$-case marked DPs

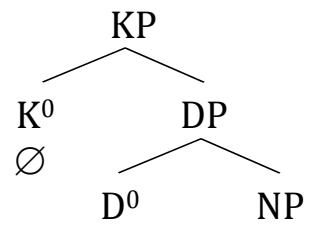


The assumption which underlies the G\&PF approach is that when $\mathrm{K}^{0}$ is empty it is subjected to the Empty Category Principle, defined after Rizzi (1990) as follows.

(27) Empty Category Principle (ECP)

A non-pronominal empty category must be properly head governed.

Since ECP holds at PF, as was argued for in Aoun et al. (1987) and Rizzi (1990) for instance, the G\&PF approach proposes that the domain of Head Government for a VO language be defined as in (28).

(28) Head Government (VO)

A head $\alpha$ governs $\beta$ iff

a. $\alpha$ precedes $\beta$, and

b. $\alpha$ and $\beta$ are contained in the same prosodic phrase $\phi$

In turn, the domain of Head Government for an OV language is defined as in (29).

(29) Head Government (OV)

A head $\alpha$ governs $\beta$ iff

a. $\alpha$ follows $\beta$, and

b. $\alpha$ and $\beta$ m-command each other

Importantly, the Head Government for a VO language involves the syntax-PF mapping rule which says to close the right bracket $(\mathrm{R})$ of a prosodic phrase when encountering a right bracket in the syntactic representation.

(30) $\phi$-Formation R (Selkirk 1986, McCarthy \& Prince 1993, Truckenbrodt 1995) 16 Align ( $\langle$ Right edge, XP $\rangle,\langle$ Right edge, $\phi\rangle)$

G\&PF, building on Zec \& Inkelas's (1990) insights that both syntactic and phonological information is accessible at the PF interface, claims that the minimal domain where case checking between $\alpha$ and $\beta$ takes place is a phrase which can be defined in narrow syntax as a syntactic phrase XP, or alternatively at PF as a prosodic phrase $\phi$. The two available case checking domains predicted by such an approach are, thus, as follows.

(31) $\alpha$ checks the case of $\beta$ iff $\alpha$ and $\beta$ are dominated by:

a. syntactic phrase XP: [xp $\alpha \beta]$, or

b. prosodic phrase $\phi: \quad\left\{_{\phi} \alpha \beta\right\}$

The choice between the two types of case checking (or case assignment, under an alternative formulation) is said to be parametric. When the case checking/assignment domain is defined as (31a), the word order surfaces as OV (as for instance Dutch); when the case checking domain is defined as (31b), the word order surfaces as VO (as for instance English), due to the availability of the mapping rule in (30) in the latter case (see Neeleman \& Weerman 1999:24-27 for a detailed discussion). The conclusion that VO languages have a prosodically defined case 
checking domain is attributed to an independently observed correlation between the head directionality of the VP and case adjacency. ${ }^{17}$ Neeleman \& Weerman (1999) report that in VO languages with null or impoverished morphological case marking, nominal objects must be phonologically adjacent to their case assigners (e.g. English, Danish, Norwegian, Berbice Dutch, Swedish, or Italian). On the other hand, case adjacency does not hold in OV languages (e.g. German, Dutch, Frisian, Japanese, Korean). In G\&PF terms, the account of case adjacency is straightforward; namely, it is required since the case checking domain in VO languages is defined prosodically. Consider for instance the VP-structures in (32a-c) and their corresponding instantiations in (33a-c).

(32) Case adjacency in VO languages

a.

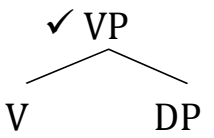

$\{\mathrm{V}$ b.

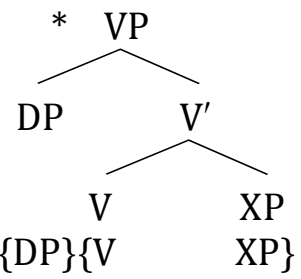

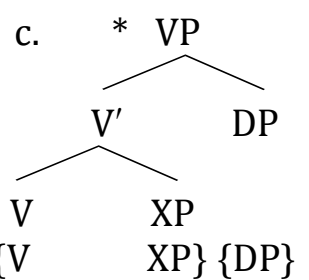

(33) a. [Jack][vp read [DP the book- $\varnothing][$ Advp quickly]] $\{$ Jack\}\{read the book $\}\{$ quickly\}

b. * [Jack][vp [DP the book- $\varnothing]$ read [Advp quickly]] $\{$ Jack $\}$ the book $\}\{$ read quickly\}

c. * [Jack][vp read [AdvP quickly][DP the book- $\varnothing]]$ $\{$ Jack $\}$ read quickly\}\{the book\}

Out of the three representations, only (32a)/(33a) is well-formed in English. This is due to the fact that, given the $\phi$-Formation rule operative in English, the object checks its case features against the verb in a prosodically defined constituent $(\phi)$, in concert with (31b). (32b)/(33b) is ruled out since the object and the verb are in separate prosodic phrases. Note that this analysis makes a correct prediction about the lack of A-scrambling in English. If prosodic adjacency must hold in an A-position, (33b) is ruled out irrespective of the fact whether the preverbal position of the object is derived by base-generation or A-movement of the DP. (32c)/(33c) is illformed since the right bracket of the AdvP is aligned with the right bracket of the prosodic phrase and the object is separated from the verb by a prosodic boundary, making case checking impossible. 18 The prosodic definition of a case checking domain in strict VO languages accounts for the adjacency requirement. On the other hand, the lack of case adjacency in strict OV languages like Dutch (cf. (34)) follows from the syntactic definition of the domain of case checking in these languages. 19

(34) The lack of case adjacency in Dutch (OV)
a. [ dat [Hans][vp [AdvP langzaam][[DP that Hans slowly
het boek- $\varnothing]$ las ]]] the book read
b. [ dat [Hans][ve [DP het boek- $\varnothing][[$ AdvP langzaam] las $]]]$ that Hans the book slowly read 
An immediate prediction behind the idea that a verb and its nominal object must form a prosodic phrase in a language like English is that a head can intervene between the case assigner and the DP-object, since a head does not have a (right) bracket in the syntactic representation. This is, indeed, a correct prediction. Consider, for instance, constructions with particle verbs.

Under the complex predicate analysis of verb-particle constructions advanced in Johnson (1991), Roeper \& Keyser (1992), or Neeleman (1994, 2002), among many others, the verb and the particle form a complex head in syntax: 20

(35) [v V Prt(P)]

Note that within the complex syntactic head as above, the particle can only optionally project (see Ackema 1995). Since $\operatorname{Prt}^{0}$ is an (adjoined) head and hence does not introduce a bracket into the representation, it does not intervene in the prosodic adjacency between the verb and the DP-object that follows the V-Prt complex:

(36) I [vp [v looked up] the word] $\{I\}\{$ looked up the word $\}$

Neeleman (2002) notes that projection is standardly allowed in syntax, but is not necessary below the $\mathrm{X}^{0}$ level. A particle in the verb-particle complex can project freely (cf. 37).

Nevertheless, according to the mapping rule in (30), whenever the particle projects the PrtP, its right bracket aligns with the right bracket of a prosodic phrase, which blocks case checking of the DP-object in the V-complement position (cf. (38)). ${ }^{21}$

(37) I [vp looked [vp the word [v $t_{V}[$ Prtp right up]]]] $\{$ I $\}\{$ looked the word $\}\{$ right $\}\{$ up $\}$

(38) * I [vp [v looked [Prtp right up]] the word]

* $\{$ I $\}\{$ looked right $\}\{$ up $\}\{$ the word $\}$

Despite the fact that G\&PF provides a principled account of a wide range of facts and makes a number of correct predictions about word order, it suffers from a major conceptual problem. Namely, it relies on a particular version of the Case Theory in which case features, though present in the syntactic representation, are checked (or assigned) at the PF interface in VO languages. This course of events cannot be true since, as is well-known, case assignment feeds A-bar movement. ${ }^{22}$ From this perspective, G\&PF's adherence to Government and Binding devices such as "ECP" and "Government", which have been reduced to principles of locality in recent approaches to syntax, seems a minor problem. 23

In what follows, we consider a modification of G\&PF, which avoids the case assignment problem and the adjacency facts follow from licensing locality. The change from a mixed OV/VO order to the strict VO order in English is argued to follow from the modified G\&PF.

\subsection{Alternative: the PF locality}

We assume a framework in which Vocabulary Insertion comes after syntax (as in Halle \& Marantz 1993, Marantz 1997, and much subsequent work on Distributed Morphology), and we propose that case is assigned always in the narrow syntax but that a prosodic sisterhood 
between the licensor and the empty morpheme is a possible licensing condition on the postsyntactic insertion of a zero exponent.

Notably, some other work on null morphemes has recognized the fact that their distribution is subject to syntactically defined locality. For instance, Emonds $(1987,2006)$ argues convincingly that a zero morpheme can be inserted only if it is a sister to a projection of its licensor. ${ }^{24}$ We propose that a locality domain for the insertion of null morphemes can be defined post-syntactically and involve prosodic sisterhood. If this idea is on the right track, then we are able to account for a connection between the impoverishment of m-case and the shift to the strict VO order in the history of English.

In the Distributed Morphology approach, which we adopt in our proposal, all morphological word formation takes place in the course of a syntactic and post-syntactic derivation, and a (functional) morpheme is a Spell-out of a (functional) syntactic head. In such an approach to morphology, the impoverishment in the inventory of functional morphemes reflects either (i) the reduction of the functional structure in syntax, i.e. a functional head is not projected, or (ii) the fact that a functional head is projected but it is phonetically empty. If Modern English nominals are like (ii), i.e. what underwent the reduction in the OE period was the phonetic exponent of the case morpheme, there exists a case head $\mathrm{K}^{0}$ in the extended projection of the NP whose exponent is zero and must be locally licensed at PF.

A consequence of this scenario is that the appearance of the zero case exponent on DPobjects has necessitated such a local licensing and has demanded that a case-assigning verb and the zero-marked DP-object be prosodic sisters. Due to the $\phi$-Formation rule for English in (30), a case-licensor must be left-adjacent to the object in order to be its prosodic sister. This can only be achieved if the surface word order is VO and no other prosodic bracket intervenes between the verb and the DP-object. Thus, given $\phi$-Formation for English and the licensing locality domain for null exponents, the loss of overt case markers has triggered the shift from mixed OV/VO in OE to strict VO.25

Importantly, there is synchronic evidence for the existence of a prosodic sisterhood between a case-assigner and a nominal with a zero case exponent. Consider for instance Turkish and Sakha, which are both OV languages and have a reverse definition of prosodic alignment than English, i.e. a prosodic phrase is closed whenever a left bracket (L) is encountered in syntax.

(39) $\phi$-Formation L (Selkirk 1995, Truckenbrodt 1999)

Align $(\langle$ Left edge, XP $\rangle$, $\langle$ Left edge, $\phi\rangle)$

In Turkish and Sakha definite nominal objects are overtly case marked and need not be prosodically adjacent to the verb (the data from Turkish is adopted from Temürcü 2001:67-68 and the Sakhan data is adopted from Vinokurova 2007).

(40) Turkish

a. Adam [vp [yavaşça] [[Dp kitab-ı ] okur ]] Adam \{yavaşça $\}$ kkitab-1 okur man slowly book-ACC reads-3.PRES

b. Adam [vp [DP kitab-1] [[ yavaşça] okur ]] Adam $\quad$ kitab-1 $\}$ \{yavaşça okur\} man book-ACC slowly reads-3.PRES 
(41) Sakha

a. Masha [vp [türgennik] [[DP salamaat-y] sie-te ]] Masha \{türgennik\} \{salamaat-y sie-te\} Masha quickly porridge-ACC eat.3.PAST

b. Masha [vp [DP salamaat-y] [[türgennik] sie-te ]] Masha \{salamaat-y\} \{türgennik sie-te\} Masha porridge-ACC quickly eat.3.PAST "It was the porridge that Masha ate quickly"

In contrast, indefinite nominal objects are zero case marked. Therefore, an indefinite and the verb must be prosodic sisters, which is indicated by the impossibility of placing the AdvP between the verb and the object, as in (42).

(42) Turkish

a. Adam [vp [ yavaşça] [ [DP kitap- $\varnothing]$ okur ]] Adam \{yavaşça\} $\quad$ kitap- $\varnothing$ okur man slowly book-ACC read-3.PAST

b. * Adam [vp [DP kitap- $\varnothing]$ [[yavaşça] okur ]] Adam $\quad$ kkitap- $\emptyset$ \} \{yavaşça\} \{okur\} man book-ACC slowly read-3.PAST

(43) Sakha
a. Masha [vp [ türgennik] [[DP salamaat- $\varnothing]$ sie-te ]] Masha \{türgennik\} \{salamaat- $\varnothing$ sie-te\} Masha quickly porridge-ACC eat-3.PAST
b. * Masha [vp [DP salamaat- $\emptyset]$ [[türgennik] sie-te ]] Masha $\quad$ salamaat- $\varnothing\}$ \{türgennik sie-te\} Masha porridge-ACC quickly eat-3.PAST

Facts like the ones in Turkish or Sakha above, thus, indicate that a locality domain for the licensing of null morphemes can be established post-syntactically at PF also in langauges which do not manifest strict word order in other contexts. This course of events is also particularly visible in a language like, for instance, Polish, which has a rich system of nominal case and which exhibits a considerable degree of word order freedom (including very local scrambling between two objects, adverbs, and the verb in double-object constructions; cf. Wiland (2009:chapter 4)). Yet, a pronominal object clitic must surface as adjacent to the verb, as shown below:
(44)
a. Paweł szybko dał mu lekarstwo. Paweł-NOM quickly gave him-CL.DAT medication-ACC
b. Paweł dał mu szybko lekarstwo. Paweł-NOM gave him-CL.DAT quickly medication-ACC
c. ?? Paweł dał szybko mu lekarstwo. Paweł-NOM gave quickly him-CL.DAT medication-ACC

In view of a syntactic approach to clitics like in Cardinaletti and Starke (1999), where 
pronominal clitics are structurally deficient nominal phrases, the adjacency facts in Polish can better understood in a theory in which adjacency exhibits a post-syntactically defined locality domain.

If our proposal that the locality conditions on the insertion of null morphemes can be defined at PF is on the right track, then the facts like those above provide synchronic evidence for our account of the diachronic facts from English. 26

\section{Predictions beyond OV/Vo}

The analysis based on the post-syntactically defined locality condition for null morphemes makes correct predictions about the rise of the following phenomena together with the loss of overt m-case in English and the shift to strict VO: (i) case adjacency, (ii) strict head-initial PPs, and (iii) exceptional case-marking constructions (ECM).

\subsection{The rise of case adjacency}

In OE, when DP-objects had m-case, case adjacency was not required. This is shown on the basis of preverbal and postverbal objects separated from the verb in (44b) and (45b), respectively.

(44) a. gif hie ænigne feld secan wolden if they any field seek wanted (van Kemenade 1987:196)

b. pæt ic pis boc of Ledenum gereorde to Engliscre spræce awende that I this book from Latin language to English tongue translate (van Kemenade 1991/93:82)

(45) a. pæt he mot ehtan godra manna that he might persecute good men (B\&R 2005, (21))

b. pæt niwe wite abregeð symble pæs mannes mod the new misery terrifies always the man's mind (cogregdC,GD_2_[C]:16.135.16.1633)

When English lost m-case, case adjacency became an obligatory constraint and in A-positions only post-verbal objects were possible. Before the $16^{\text {th }}$ century, postverbal objects could still be separated from the transitive verb, as in (46a-b). After the $16^{\text {th }}$ century, constructions like the one in (47) with a postverbal object separated from the verb were unattested.

(46) a. Than sir Launcelot had a condicion then sir Launcelot had a condition (Thomas Malory's Morte Darthur, 1460-70)

b. but thei waisschen ofte her hoondis but they wash often their hands (Wycliffite Bible, $14^{\text {th }} \mathrm{c}$.)

(47) * but they wash often their hands

In view of our discussion of case adjacency, these facts indicate that in the OE period the insertion of overt case exponents did not require prosodic sisterhood as a locality domain. In other words, objects could surface freely within the c-command domain of the Accusativeassigning head (which we attribute to the little $\mathrm{v}^{0}$ ) as we see in (48) and (49): 
(48) a. [ gif [ hie] [[vP [DP ænigne feld] secan ] wolden]] if they any field seek wanted

b. [ pæt [ic] [vP [DP pis boc ][PP of Ledenum gereorde] [PP to Engliscre spræce]] that I this book from Latin language to English tongue awende]] translate

(49) a. [ pæt [he] [mot [vp ehtan [DP godra manna ]]] that he might persecute good men

b. [ pæt niwe wite][vP abregeð [AdvP symble][DP pæs mannes mod]] the new misery terrifies always the man's mind

When prosodic sisterhood became a condition on the insertion of null morphemes, the DPobject had to be right-adjacent to the verb:

(50) Then [Sir Launcelot] [vP had [DP $\varnothing$-a condition]] Then $\{$ Sir Launcelot $\}\{$ had a condition $\}$
* [they][vp wash [AdvP often] [DP $\varnothing$-their hands]] * $\{$ they $\{$ wash often $\}$ their hands $\}$

\subsection{The rise of strict head-initial PPs}

In the OE period when DP-objects had m-case, both P-final and P-initial PPs were attested, as in $(52 \mathrm{a}, \mathrm{b})$ respectively. 27

(52) a. And Eadric ealdorman gewende ba pone cyning ongean æt Æglesforda and Edric Alderman turned then the king against at Aylesford (cochronD,ChronD_[Classen-Harm]:1016.74.1675)

b. Gebletsod is se pe com on Godes naman blessed is he who came in God's name (van Kemenade 1987:114, (8a))

Once English lost m-case, head-initial PPs became the only attested pattern, like in (53).

(53) they did not dare pray for the sinners

The reason why both head-final and head-initial PPs were attested in OE but the former disappeared in later periods again has to do with overt case marking. Namely, a prosodic sisterhood must hold between a zero-marked DP and any case-assigning head, $\mathrm{v}^{0}$ or $\mathrm{P}^{0}$ :

(54) a. vP: $\quad\left\{{ }_{\phi} \mathrm{v}^{0} \mathrm{DP}-\varnothing\right\}$

b. PP: $\quad\left\{_{\phi} \mathrm{P}^{0} \mathrm{DP}-\varnothing\right\}$

(Note that our analysis of case adjacency does not offer an account of the lack of pre-verbal PPs in Modern English. Since PPs do not have case exponents, VP-internal PP-scrambling cannot be ruled out by case-theoretic reasons). 


\subsection{The rise of ECM constructions}

ECM constructions are usually claimed to be unattested in OE (see Lightfoot 1991:81ff.). The emergence of ECM is dated to late ME, i.e. approximately the $15^{\text {th }}$ century (see for instance Warner 1982). Example (55b) comes from the $15^{\text {th }}$ century, while (55b) from the $16^{\text {th }}$ century.

(55) a. [S]he dare not aventure here money to be brought vp to London for feere of robbyng

she dare not venture her money to be brought up to London for fear of robbing (Paston Letters 156.7)

b. I desire you to shew me where ye have ben

I desire you to show me where you have been

(Ld. Berners Huon lxi. 212)

In our terms, the account of the rise of ECM is straightforward. Once English lost overt case exponents, then for an embedded subject to be case-licensed by the matrix little $\mathrm{v}^{0}$ it must become its prosodic sister.

On this view, raising-to-object constructions in Modern English are not necessarily derived by the presence of a movement diacritic like the "EPP-feature" on a Accusative-assigning head (as it is proposed in Lasnik 1999, 2003), but rather two (sort of) independent steps. The first one involves movement out of the embedded $\mathrm{CP}$, which, although defective, constitutes a barrier to external probing from the matrix little $v^{0}$ (in concert with the Phase Impenetrability Condition (Chomsky 2001)). 28 The second step involves the licensing of the null case exponent under a prosodic sisterhood with the matrix little $\mathrm{v}^{0}$. The derivation can be represented as follows.

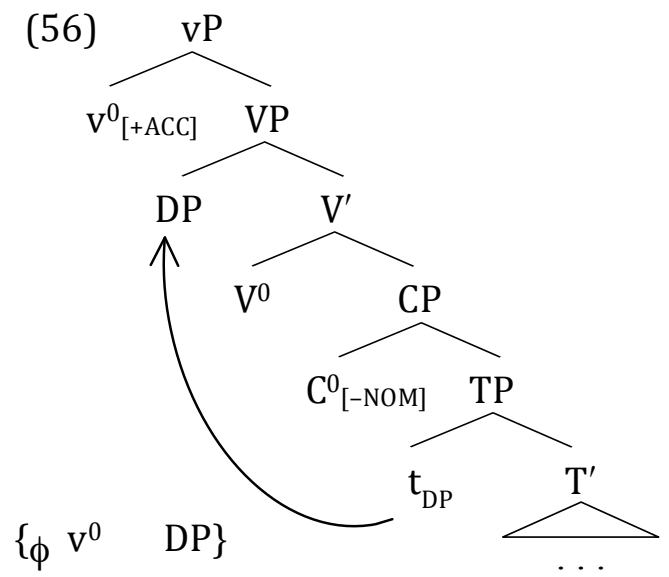

An argument for prosodically constrained ECM constructions comes from a well-known fact that no adverb or intonational break may intervene between the matrix verb and the embedded subject as in (57), just like no prosodic intervener is allowed between a transitive verb and a DP-object in simple transitive constructions.

(57) a. George believed Mary sincerely to be a liar.

b. * George believed sincerely Mary to be a liar.

c. We suspected him incorrectly to have been involved in the arson.

d. * We suspected incorrectly him to have been involved in the arson. 
Indeed, even the earliest attestations of ECM appear only with case adjacency, like the ones in (58a,b).

(58) a. I [vp desire [you] [to shew me ... ]]

I desire you $\{$ to shew me\}...

b. He [vp needed [no iudge][to goe vpon him ...]]

He $\{$ needed no iudge $\quad$ to goe vpon him $\} \ldots$

\section{Apparent challenges to the PF-locality account}

In this section we briefly discuss three selected issues which seem to be at odds with our proposal developed above. We mention them to show that these issues are only apparently problematic and do not in fact undermine any of our major arguments. Below, we first deal with some apparent counterevidence from the history of Germanic, specifically from Dutch and German. The following two questions are raised in this context: why both Dutch and German fixed their word order, whereas supposedly only Dutch has lost m-case on nominals, and why both Dutch and German fixed their word order as strict OV, whereas English fixed its word order as strict VO. Next, point out that adjacency netween $V$ and $O$ turns out to hold also in those strict VO languages which involve V-raising to the IP- or CP-area of the clause, when the bottom copy of the raised verb is considered. We then consider an apparently problematic fact from the history of English, namely that surface OV orders could still be found at a stage when English was already a strict VO language.

\subsection{Why Dutch and German are strict word order languages}

The first apparent problem concerns one of the underlying claims of our account, namely that the loss of m-case unavoidably leads to the fixation of word order. This claim has been explicitly challenged, e.g. by Barðdal (2009) and McFadden (2005), based on the comparison of the changes that took place in the histories of Dutch and German.

According to McFadden (2005), the diachronic facts from Dutch and German indicate that the presence or absence of $m$-case does not influence the freedom of word order in a given language. McFadden (2005) observes that if rich m-case were a determining factor for word order patterns, we should expect Dutch (which has lost m-case in its history) to pattern differently from German (which has preserved m-case until nowadays). Both languages, however, followed a strikingly similar development in word order, i.e. they changed from mixed OV/VO languages to strict OV languages. McFadden (2005) finds these facts contradictory and concludes that the presence or absence of m-case has no effect on the freedom of word order, at least at the clause level.

The conclusion McFadden reaches is, nevertheless, wrong. The flaw of his argument stems from a misinterpretation of the morphological facts from German. Although nominals in Modern German are not devoid of overt inflection, the system of $\mathrm{m}$-case in Modern German is less robust than the m-case system in earlier periods of German, specifically in Old High German. Table 1 includes the singular number inflectional paradigm of Bote 'messenger'. The suffixes in three respective columns come from three historical periods of German, i.e. Old High German (700 AD-1100 AD) Middle High German (1100 AD-1350 AD), and Modern High German (i.e. $1350 \mathrm{AD}-.$. ). 
Table 1. Inflectional paradigm of the nominal Bote 'messenger'-Sg in three historical periods of German

\begin{tabular}{|l|l|l|l|}
\hline & Old High German & Middle High German & Modern High German \\
\hline Nom & Bot-o & Bot-e & Bot-e \\
\hline Gen & Bot-en & Bot-en & Bot-en \\
\hline Dat & Bot-en & Bot-en & Bot-en \\
\hline Acc & Bot-on & Bot-en & Bot-en \\
\hline
\end{tabular}

The table demonstrates that there has been some leveling of nominal inflections throughout the history of German. Whereas in Old High German three distinct forms were used to mark four cases, in Middle High German the number of distinct forms was reduced to two and this carried over to the Modern High German period. Admittedly, German has not lost nominal inflection altogether. What is significant, however, is that it has undergone visible reductions in overt case-marking. In the context of what has been advanced in section 4.2 , the reduction in $\mathrm{m}$-case which has affected German nominals is tantamount to the reduction in their functional structure. This accounts for why German imposes restrictions on word order, analogously to Dutch. ${ }^{29}$ In the following section we provide an account of why both German and Dutch fixed their word order as strict OV, rather than strict VO like English.

\subsection{Why Dutch and German are strict OV languages}

The next problem concerns Dutch and German again. This time, however, the question is about the reason for which these languages pattern together to the exclusion of English with respect to OV/VO. Taking into account that English and Dutch lost m-case marking on nominals while German at least reduced it, and that, as we argue, such changes in m-case do impose constraints on word order, it is unclear why the three languages constrained their word orders differently.

There are good reasons to attribute the difference between English, on the one hand, and Dutch and German, on the other, to the head-directionality of the phrase which immediately dominates the vP (we simply assume here that some projection of the IP-domain constitutes such a phrase, i.e. TP, AgrP, or other, depending on the degree of the articulation of the IPdomain in these languages). Following Holmberg (2000), we take the head-directionality of phrases to be regulated by the Final-over-Final Constraint (FOFC), as in (59). ${ }^{30}$

(59) Final-over-Final Constraint (Holmberg 2000)

a. If $\alpha \mathrm{P}$ is a head-final phrase and $\beta \mathrm{P}$ is a phrase immediately dominating $\alpha \mathrm{P}$, then $\beta \mathrm{P}$ can be head-initial or head-final.

b. If $\alpha \mathrm{P}$ is a head-initial phrase and $\beta \mathrm{P}$ is a phrase immediately dominating $\alpha \mathrm{P}$, then $\beta$ P must be head-initial.

Translating FOFC into the context of OV/VO, i.e. translating $\alpha \mathrm{P}$ into vP and $\beta \mathrm{P}$ into IP, allows us to account for the spectrum of word order patterns found cross-linguistically. As reported by Biberauer et al. (2007), languages exhibit word order patterns in 60(a-c) but rarely, if ever, employ the pattern in (60d). This is compatible with FOFC insofar as (59a) allows both (60a) and (60b), while (59b) allows (60c) but rules out (60d). 
(60) a. [Aux [0 V]] head-final $\alpha \mathrm{P} \&$ head-initial $\beta \mathrm{P}$

b. $[[0 \mathrm{~V}]$ Aux $]$ head-final $\alpha \mathrm{P} \&$ head-final $\beta \mathrm{P}$

c. $[$ Aux [V 0]] head-initial $\alpha \mathrm{P} \&$ head-initial $\beta \mathrm{P}$

d. * [[V 0] Aux $]$ head-initial $\alpha \mathrm{P} \&$ head-final $\beta \mathrm{P}$

Crucially, the orders (60a) and (60c) are relevant in connection with the diachronic facts from English. At the time when English lost m-case on nominals, the English vP was dominated by a head-initial IP. Given FOFC, the presence of a head-initial IP allowed for two possibilities of linearization, i.e. OV or VO. However, given the alignment rule for prosodic phrase formation (cf. (30)), VO was the only order which satisfied the PF locality condition.

The orders (60b) and (60d) are, in turn, relevant in connection with Dutch and German. At the time when these languages lost/reduced their m-case marking, their vPs were dominated by head-final IPs. Given FOFC, this excluded the possibility of strict VO and necessitated strict OV. What is more, the choice of OV entailed that Dutch and German did not introduce the requirement of case adjacency. This is illustrated by examples in $(61 \mathrm{a}, \mathrm{b})$ from Modern Dutch and (62a,b) from Modern German. Of special importance are examples (61b) and $(62 \mathrm{~b})$, where the verb and the object are separated by the adverb.

(61) a. [dat [Peter] [vP [langzaam] [[DP het boek] las ]]] that Peter slowly the book read

b. [dat [Peter] [vP [DP het boek] [[ langzaam] las ]]] that Peter the book slowly read

(62) a. [dass [Peter] [vp [ langsam] [[DP das Buch] las ]]] that Peter slowly the book read

b. [dass [Peter] [vp [DP das Buch] [[ langsam] las ]]] that Peter the book slowly read

Based on the assumption that both Dutch and German employ the same syntax-PF alignment rule as English (cf. (30)), verbs and objects in these languages can never be prosodic sisters. No matter whether the verb and the object are adjacent to each other on the surface, as in (61a) and (62a), or whether they are separated by some lexical material, as in (61b) and (62b), the verb and the object are always in different prosodic phrases. This, in effect, rules out the possibility of local licensing at PF. What this indicates is that the lack of a post-syntactically defined locality domain in Dutch and German stems from an overriding effect of FOFC. In other words, in these two languages FOFC overrides prosodically defined locality. 31

\subsection{Adjacency in strict Vo languages broken up by verb movement}

An apparent problem for a theory postulating an adjacency requirement between the verb and the DP-object comes from strict VO languages with V-raising to the IP- or CP-system, like Icelandic, French, or Mainland Scandinavian. ("V-raising" shall be understood here broadly, either as an instance of syntactic head movement, or remnant movement of a larger constituent of which the verb is the only phonologically realized element). However, as pointed out in Neeleman \& Weerman's and subsequent work on adjacency, such languages exhibit adjacency between the trace or copy of the verb and the DP-object. This becomes visible in constructions in which V-movement does not take place (in contexts without verb-second, or when verb 
raising is blocked by the presence of an auxiliary). This is illustrated by Icelandic examples below, where adjacency must hold between $\mathrm{V}$ and $\mathrm{O}$ when $\mathrm{V}$-raising does not take place.

(63) a. Jón \{hefur lesið bækurnar\}\{rækilega\} John has read the-books thoroughly

b. * Jón \{hefur lesið rækilega\} \{bækurnar\}

John has read thoroughly the-books (Neeleman 2002:148)

Such constructions, thus, indicate that adjacency between (copies of) $\mathrm{V}$ and $\mathrm{O}$ are relevant in the domain where licensing between these two elements applies, i.e. in the v/VP.

\subsection{Why English with strict VO allowed surface $\mathrm{OV}$ orders}

The last problem concerns the existence of surface OV orders in the period(s) in which English was already a strict VO language. We first discuss this issue with reference to English only and subsequently relate it to some other languages where a similar phenomenon may be observed.

There appears to be some inconsistency in claims concerning the fixation of VO vis-à-vis the loss of OV in the history of English. On the one hand, it is often maintained that strict VO was established around the $12^{\text {th }}$ century. On the other hand, it is also well-known that surface OV orders were not radically absent in later periods; for instance, surface OV orders were still attested as late as the $15^{\text {th }}$ century (see Foster \& van der Wurff 1995, Kroch \& Taylor 1994, 1998, McFadden 2005, van der Wurff \& Foster 1997). At first sight, this is not what is straightforwardly predicted by our theory, according to which nominal objects in strict VO languages cannot be licensed in the preverbal position. However, a closer look at the English data from the relevant periods reveals that the facts are more complex.

Table 2 contains the statistical data concerning the frequency of surface OV orders in two periods of English, i.e. OE and ME. OE is further divided into two subperiods (OE1, OE2), and ME splits into four subperiods (ME1, ME2, ME3, ME4). The figures central to the current discussion are given in bold. As they demonstrate, the frequency of surface OV orders attested in the periods in which English was devoid of m-case, i.e. in the periods postdating 1200 (ME2, ME3, ME4), is different for different types of objects. Strikingly, the majority of surface OV orders in these three periods involve non-positive objects, i.e. negative objects $(18.2 \%$ in ME2, $20.3 \%$ in ME3, 22.0\% in ME4) or quantified objects (10.6\% in ME2, 6.0\% in ME3, 6.1\% in ME4). Positive preverbal objects are in the minority and show a decreasing tendency $(3.1 \%$ in ME2, $1.3 \%$ in ME3, $0.7 \%$ in ME4). 32

Table 2. Frequency of preverbal objects in OE and ME (see Pintzuk \& Taylor 2006:259)

\begin{tabular}{|c|c|c|c|}
\hline Period & Positive $\mathrm{DP}_{\mathrm{Obj}}$ & Negative $\mathrm{DP}_{\mathrm{Obj}}$ & Quantificational DP ${ }_{0 b j}$ \\
\hline OE1 ( ...-950) & $56.7 \%$ & $91.8 \%$ & $63.5 \%$ \\
\hline OE2 (950-1150) & $50.4 \%$ & $78.3 \%$ & $56.4 \%$ \\
\hline ME1 (1150-1250) & $28.4 \%$ & $41.0 \%$ & $34.7 \%$ \\
\hline ME2 (1250-1350) & $3.1 \%$ & $18.2 \%$ & $10.6 \%$ \\
\hline ME3 (1350-1420) & $1.3 \%$ & $20.3 \%$ & $6.0 \%$ \\
\hline ME4 (1420-1500) & $0.7 \%$ & $22.0 \%$ & $6.1 \%$ \\
\hline
\end{tabular}

In (63) and (64) we give a number of illustrative examples of surface OV from the $15^{\text {th }}$ century. Examples in (63) involve negative objects, and examples in 64 involve quantified objects (data 
taken from Moerenhut \& van der Wurff 2000:518-520 and van der Wurff 1999:241).

(63) a. and they woold nowte do fore hem 'and they would do nothing for them'

b. I kowd no rest have in myn hert 'I had no peace in my heart'

(64) a. whethye ye haue eny thing spoken of my going to Caleys 'whether you have said anything about my going to Calais'

b. for he may al pynge do 'for he can do everything'

As observed in the literature, an analogous phenomenon can be observed in a number of other languages which are otherwise strict VO, notably in Scandinavian. Examples in (65)-(66) illustrate two contexts in which Modern Icelandic requires or allows surface OV. Examples $(65 a, b)$ show that $\mathrm{OV}$ is obligatory for negative objects, while $(66 \mathrm{a}, \mathrm{b})$ show that $\mathrm{OV}$ is possible but not required for quantified objects (data taken from Thráinsson 2007:84).

(65) a. Ég hef enga bók lesið I have no book read

b. *Ég hef lesið enga bók I have read no book

(66) a. Jón hefur ýmsar bækur lesið John has various books read

b. Jón hefur lesið ýmsar bækur John has read various books

Although the correspondence between Modern Icelandic and fifteenth-century English is not perfect (e.g. contrary to Modern Icelandic, fifteenth-century English did not require surface OV for negative objects), the data adduced above are quite telling. The similarity at hand is discussed in some detail by van der Wurff (1999), who mentions two further contexts in which both languages employ surface $\mathrm{OV}$ orders, i.e. relative clauses and coordinate clauses. For reasons of space, we do not discuss such contexts here. Let us only add that surface OV orders involving negative objects may also be found in other Scandinavian languages, though they are considerably less productive than in Modern Icelandic. (67) from Modern Danish and (68) from Modern Norwegian are given as an illustration. Such examples are judged differently by speakers of these languages: some speakers judge them as marked or old-fashioned, whereas for others they are rather unacceptable (see Svenonius 2000:284ff.).

(67) Jeg havde ingen penge fået den dag I had no money got that day (Diderichsen 1946:1987)

(68) Jon har ingen romanser lest John has no novels read (Christensen 1986:28)

In Englsh, surface OV orders with positive objects were not entirely absent in the critical periods (ME2, ME3, ME4), as exhibited in Table 2, as well as an example in (69) (taken from Roberts 1997:425-526, fn. 7). 
(69) She did him excite ... hir story for to write she did him excite her story for to write

Roberts (1997, fn. 7, fn. 10) notes that such examples are mostly found with infinitives and participles (see also van der Wurff 1999:243-244). He admits at the same time that their analysis is unclear. Whilst we do not have any account for such constructions either, we think that their incidence is low enough to treat them as residual. Pending future research into this area, we thus suggest to view them as non-productive remnants from earlier stages of English. See van der Wurff (1997:138-139).

When it comes to surface OV orders with negative or quantificational objects, we suggest that they are amenable to an $\mathrm{A}^{\prime}$-movement analysis along the lines of Negative Movement and Quantifier Movement in Modern Icelandic (see Jónsson 1996, Svenonius 2000). The fact that OV orders are mostly found with this type of DPs substantiates such a treatment, considering that both Negative Movement and Quantifier Movement are presumably motivated by rules of semantic interpretation. An attempt at developing an analysis of this type applicable to fifteenth-century English can be found in van der Wurff (1999). ${ }^{33}$

\section{Final remarks}

We have argued for an account of the shift to strict VO in English which follows from a theory of post-syntactically defined locality. Such an approach provides an answer to the two fundamental questions, namely why English ceased to be a mixed OV/VO language, and why it developed strict VO rather than strict OV.

The theory also makes a number of predictions beyond OV/VO. Specifically, it captures the fact that the shift to the strict VO order, in English but not only, coincides with a number of other changes (we have discussed three such changes, i.e. the rise of case adjacency, the shift to strict head-initial PPs, and the emergence of ECM constructions). As far as we are aware, none of the analyses proposed earlier connects straightforwardly with these questions and facts.

The theory advanced here is mostly based on empirical facts from English and detailed research into other languages is needed to evaluate its accuracy on a larger scale. As always, a number of loose ends remain. For instance, it remains to be figured out what factors are responsible for eliminating the variation in the head-directionality of the projections in the IPsystem. Given that earlier periods of English, very much like earlier periods of Dutch and German, allowed both head-initial and head-final IPs, the question arises why this variation could not be maintained for longer than it was. Even though the theory advanced here does not offer a ready-made answer to this question, it nevertheless throws light on many other facts which have remained puzzles under other proposals.

\section{Notes:}

1 Some percentages regarding the frequency of surface OV orders in OE and ME are given in Table 2 in section 6.3.

2 This context allows us to obtain a reliable indication of the placement of the non-finite verb, on the assumption that in such a context the non-finite verb remains in its base- 
generated position within the VP. The finite verb is assumed to move, in both main and embedded clauses, which makes the task of determining its underlying position more difficult.

3 Although Pintzuk (2005) records three constructions corresponding to V-Obj-Aux in the OE data, she claims that the order must be considered ungrammatical due to its scarce attestation. More generally, Biberauer et al. (2007) observe that V-Obj-Aux is unattested in Germanic, Finnish, and Basque. They claim that although some Central Sudanic languages, e.g. Ma'di and Lugbara, apparently allow this order, it may be due to the nominal nature of auxiliaries in these languages. However, Svenonius (2000:21, fn. 5) mentions two BongoBagirmi languages, i.e. Ngambay and Mbaye, in which V-Obj-Aux is possible and in which auxiliaries are verbal rather than nominal.

4 There are potential risks behind such generalizations, though. Language change is hard to grasp chronologically insofar as it cannot be described in terms of specific points in time. We are also aware of the problems inherent in any statements concerning a given language as a homogenous entity, without taking into account such aspects as dialectal variation. The position defended in this paper is defended on the basis of the generalized set of data.

5 While there is a rich body of literature devoted to typological implications regarding $\mathrm{OV} / \mathrm{VO}$, particularly in the context of Greenbergian universals, their discussion lies outside the scope of this paper. A few representative references are given here for the interested reader, e.g. Dryer (1992), Hawkins (1983), Lehmann (1973), Vennemann (1974).

6 Pintzuk (2002) also opposes the idea that m-case may have an effect on word order. A similar argument is made by by Sundquist (2002) on the basis of the diachronic facts from the Mainland Scandinavian languages.

7 Importantly, we follow Neeleman \& Weerman (1999) in that we take the correlation at hand to hold in one direction only. That is, whereas the presence of m-case allows for the coexistence of $\mathrm{OV}$ and $\mathrm{VO}$ orders, there is nothing which precludes the existence of a language with m-case and strict OV or strict VO.

8 A reader interested in older studies which support the treatment of OE as OV is referred, e.g. to Bean (1983), Canale (1976, 1978), Lightfoot $(1979,1991)$, Stockwell (1977).

${ }^{9}$ Van Kemenade (1987) assumes that the finite verb originates directly in the head of the IP. This is different from many other proposals, according to which such verbs are basegenerated in the head of a separate VP and move to the head of IP later. Nothing hinges on the choice between the two options.

10 Biberauer \& Roberts $(2005,2006)$ follow the standard minimalist practice, according to which vP (a phase) is universally present in the structure and that $\mathrm{V}^{0}-$ to $^{-} \mathrm{V}^{0}$ movement is universally required in order to verbalize the acategorial root (Chomsky 2004). We emphasize this because in Fuss \& Trips's (2002) analysis, presented in section 3.3, neither vP nor $V^{0}-$ to- $^{0}$ movement is always required. 
11 In this context see the Constant Rate Hypothesis (Kroch 1989), which predicts that when grammatical systems compete with each other, the frequency of their usage may be different in different contexts, but their rate of change over time will be the same in all contexts.

12 Kroch \& Taylor (1997) point out that Pintzuk's (1991) analysis is problematic insofar as it:

(i) allows embedded clauses with V2 to begin with topics; this is at odds with the OE data, where the majority of embedded clauses with V2 begins with subjects rather than topics

(ii) resorts to a special clitic-inversion rule which places pronouns between the topic and the verb in V2; not only is this rule theoretically unjustified but it also has no counterpart among Germanic (see also Kiparsky 1996, fn. 28)

13 Fuss \& Trips's (2002) proposal was meant to be an improvement on Pintzuk's (1991) account. They note that Pintzuk's (1991) analysis is problematic because it:

(i) does not predict the different placement of adverbs in main and embedded clauses: in main clauses adverbs cannot intervene between pronominal subjects and V2 (i.e. Subj-V-Adv vs. *Subj-Adv-V), while in embedded clauses such an intervention is possible

(ii) resorts to a stipulation to block the derivation of the order V-Obj-Aux

14 Crucially, Fuss \& Trips (2002) maintain that the presence of vP is not universal but if $\mathrm{vP}$ is present $\mathrm{V}^{0}$-to- $\mathrm{v}^{0}$ movement is required.

15 As for Roberts (1997), his claim that the shift to VO resulted from the loss of object movement and this in turn resulted from the relevant features becoming weak seems to be based on a st ipulation. If overt object movement depended on the presence of m-case marking on nominals, we would expect very few VO orders attested in the period in which English nominals possessed such marking. Actually, given Roberts's assumption about focus and case checking, VO orders in OE would be restricted to focus-bearing objects. Moreover, as Pintzuk (2005) observes, an increase in VO orders in late OE would presumably imply that speakers used more focused objects than in early OE.

16 See also Wagner (2005) for a more recent approach to syntactically conditioned prosody.

17 The observation that in certain languages, including English, nominal objects must be phonologically adjacent to their case-assigner (a transitive verb or a preposition) was made at least as far back as Stowell (1981). Despite the wide recognition of this fact, it did not receive a principled account before. 
18 Note also that while the traditional Head-Parameter approach can rule out 33b, it fails to rule out 33c straightforwardly and must make an auxiliary stipulation about the ban on the placement of overt material between the verb and the object in the surface representation.

19 In other words, alternative definitions of the case checking domain in VO- and OVlanguages account for the fact that the linearization of the VP-material in a VO-language does not mirror the linearization of the VP-material in an OV-language, as indicated by the adjacency facts.

20 See Zeller (2001) and Dehé (2001) for overviews of problems with an alternative small clause analysis of particle verbs, advanced for instance in DenDikken (1995). One of the most serious challenges to the small clause analysis, which at the same time supports the complex predicate analysis, is the possibility of coordinating a particle verb with a simplex verb:

(i) The recipe says to chop up and sauté three big onions.

In the present paper, we assume that the verb and the particle form a complex head in syntax, though it remains to be investigated whether G\&PF is also compatible with the small clause analysis of constructions with particle verbs.

21 We disregard the derivational steps of (37) and the exact label of the projection to which the verb moves. There exist numerous proposals of how to derive constructions with a stranded particle (if the particle is indeed stranded in such constructions) pursued within different frameworks of assumptions about the clause structure. What is relevant here is the contrast between (37) and (38), which, as far as we can see, cannot be accounted for without the consideration of the surface representation of the syntactic structure.

22 The fact that case assignment feeds A-bar movement, often taken to be illustrated by examples like in (i) or (ii) below, constitutes a challenge not only to G\&PF but also to other configurational approaches to case assignment such as, for instance, Marantz (1991).

(i) What $[$ тр $<$ what $>$ was stolen $<$ what $>]$ ?

(ii) a. It is known who [ $<$ who $>$ was told $<$ who $>$ that he would be fired].

b. * Who is known $<$ who $>$ [(that) it was told $<$ who $>$ that he would be fired].

(from Abels 2007)

23 Such an alternative account of adjacency, among other things, avoids the problem of case checking or assignment feeding subsequent $A$ '-movement of the DP, which challenges the original G\&PF account. The problem has to do with (zero case-marked) DPs raised from their case positions by some A'-movement, which disrupts adjacency and which creates an apparent challenge to any theory postulating such a requirement. But while the post-syntactically defined licensing locality can in principle apply to a copy of a raised DP in its case position avoiding in this way the disruption problem, such a solution is not available to the G\&PF 
account which postulates post-syntactic case checking/assignment. This is so since there is nothing that prevents case checking or assignment to apply to the lower copy of the DP in a movement chain which includes also higher copies of the DP (in some A'-positions). Yet, instances of improper movement teach us that case checking must essentially take place before another $\left(\mathrm{A}^{\prime}\right)$ copy of the DP is created in the DP movement chain.

24 Emonds' $(1987,2006)$ local licensing of null morphemes is conditioned by the Invisible Category Principle and Generalized Local Identification, defined as follows:

(i) Invisible Category Principle

$\alpha$ can be empty iff all marked canonical features $\mathrm{F}$ of $\alpha$, except perhaps $\alpha$ itself, are identified.

(ii) Generalized Local Identification

Let $\gamma=\alpha$ or $\operatorname{Spec}(\alpha)$. We say that $\beta^{0}$ identifies a feature $F$ of $\gamma$ iff $F$ is present in $\beta^{0}$, where some projections $\beta^{\mathrm{i}}$ and $\alpha^{\mathrm{j}}$ are sisters.

25 Note once again that this conclusion does not depend on, nor argues against, any particular syntactic scenario in which the surface VO word order is derived. What it communicates, if correct, is that an output of a syntactic derivation must feed PF in a particular way for a particular reason.

26 McFadden (2004) on the basis of the Japanese example like below suggests an analysis of the relation between the null morpheme and word order which departs from licensing locality.

(i) a. John-ga dare-(o) nagutta no? John-NOM who-(ACC) hit Q "Who did John hit?"

b. Dare-*(o) John-ga nagutta no?

In $\mathrm{i}-\mathrm{a}$, either - $o$ or zero can mark the Accusative when the Accusative NP is adjacent to the transitive verb. In $i-b$, where the Accusative NP is topicalized and separated from the verb, the Accusative can only be marked by - 0 . McFadden (2004:185) suggests that all that needs to be said about facts like above is that an overt case marker must be inserted on objects which have moved out of a certain domain (say, the VP), while both an overt or a zero case marker is available for objects that remain inside that domain (the VP). We remain sceptical about such an alternative for the following reason. While indeed the Accusative NP has moved out of the VP in $\mathrm{i}-\mathrm{b}$ above, the claim that the insertion of a zero case exponent is conditioned by the lack of movement out of the VP (or some other constituent) does not explain the adjacency facts of the type found in Turkish or Sakha discussed in this section. The minimum requirement for McFadden's proposal to work would be to abstract away from surface representations in i-a,b in the case of Japanese, and in (40)-(43) in the case of Turkish and Sakha, and to show that: 
- sometimes the object moves across the VP adverb, as in (40b) or (41b), but

- sometimes it does not, as in (40a) or (41a), and

- that the movement of the nominal object across the adverb has consequences for case marking

On top of that, an analysis along this line must also explain why it is the zero exponent of the Accusative that cannot be inserted in the context of movement (cf. (42b), (43b)), while the overt exponent of the same case can be inserted in both contexts (cf. (40b), (41b)). Moreover, such an alternative disconnects with case adjacency facts (including the facts from English) and leaves them unexplained. We leave these issues as challenges to be accounted for by practitioners of the approach based on phrase sensitivity.

27 The incidence of head-initial PPs in OE was low, but what matters for the present analysis is the fact that they were not uniformlly ill-formed, contrary to what we observe in later periods.

28 Obviously, the fact that infinitival CPs are barriers for case assignment is not merely a conceptual consequence of adopting the Phase Impenetrability Condition but rather an independent observation. It has, for instance, motivated the "null case" theory of PRO, on the grounds that the presence of the CP-layer shields PRO from getting a case from the matrix verb (cf. Chomsky and Lasnik 1993).

29 Apart from the diachronic evidence, there are also synchronic reasons supporting the claim that m-case marking in Modern German is not sufficiently robust. For details see Neeleman \& Weerman (1999).

30 Holmberg's (2000) Final-over-Final Constraint captures a good deal of empirical facts, though it seems to simply restate them in a formalized way. For some attempts at explaining the universal validity of FOFC see, e.g. Biberauer et al. (2008), Cecchetto (2008), and Tokizaki \& Kuwana (2008).

31 It remains a question for further study whether these languages employ a syntactically defined locality condition on the insertion of null morphemes as advanced in Emonds' work $(1987,2006)$. We leave this issue unresolved at this point.

32 The figures in Table 2 are based only on prose texts. As is often the case, the language of poetry preserves more archaic traits and so surface OV orders are more frequently found there (see van der Wurff 1999:241, fn. 2).

33 In this connection, note also that our approach does not radically exclude the existence of surface OV orders in otherwise strict VO languages, such as those involving clitic pronouns in Modern French or surface VO orders in otherwise strict OV languages, such as those involving extraposition of heavy elements in Modern Dutch. 


\section{References:}

Abels, K. 2007. Some implications of improper movement for cartography. Ms., UCL.

Ackema, P. 1995. Syntax below zero. Utrecht University dissertation/LOT Dissertation series.

Allard, E. 1937. Een grammaticaal onderzoek van het proza van Hadewych. Nijmegen: KUN.

Allen, C. 1995. Case marking and reanalysis: Grammatical relations from Old to Early Modern English. Oxford: Oxford University Press.

Aoun, J., N. Hornstein, D. Lightfoot, and A. Weinberg. 1987. Two types of locality. Linguistic Inquiry 18.537-77.

Aronoff, M. 1976. Word formation in generative grammar. Cambridge, MA: MIT Press.

Barðdal, J. 2009. The development of case in Germanic. In The role of semantics and pragmatics in the development of case, J. Barðdal and S. Chelliah (eds), 123-159. Amsterdam: John Benjamins.

Bean, M. C. 1983. The development of word order patterns in Old English. London \& Canberra: Croom Helm.

Biberauer, T., and I. Roberts. 2005. Changing EPP parameters in the history of English: Accounting for variation and change. English Language and Linguistics 9.1:5-46.

Biberauer, T., and I. Roberts. 2006. The loss of 'head-final' orders and remnant fronting in Late Middle English: Causes and consequences. In Comparative Studies in Germanic Syntax: From A(frikaans) to Z(ürich German), J. M. Hartmann and L.Molnárfi (eds), 263-297. Amsterdam: Benjamins.

Biberauer, T., A. Holmberg, and I. Roberts. 2007. Disharmonic word order systems and the Final-over-Final Constraint (FOFC). To appear in Proceedings of Incontro Grammatica Generativa.

Biberauer, T., A. Holmberg, G. Newton, I. Roberts, and M. Sheehan. 2008. Impossible changes and Impossible borrowings: The Final-over-Final-Constraint. Paper presented at Continuity and Change in Grammar, Cambridge University.

Bittner, M., and K. Hale. 1996. The structural determination of case and agreement. Linguistic Inquiry 27:1-68.

Bouchard, D. 2002. Adjectives, number and interfaces: Why languages vary. Oxford: Elsevier Science.

Canale, W. M. 1976. Implicational hierarchies of word order relationships. In Current progress in historical linguistics. W. J. Christie (ed.), 39-69. Amsterdam: North-Holland.

Canale, W. M. 1978. Word order change in Old English: Base reanalysis in generative grammar. University of Toronto dissertation. 
Cardinaletti, A., and M. Starke. 1999. The typology of structural deficiency: A case study of the three classes of pronouns. In Clitics in the languages of Europe, H. van Riemsdijk (ed.), 145-233. Berlin: Mouton de Gruyter.

Cecchetto, C. 2008. Backward dependencies constrain linearization (but not too much). Paper presented at GLOW, University of Newcastle.

Chomsky, N. and H. Lasnik. 1993. The theory of Principles and Parameters. In Syntax: An international handbook of contemporary research, J. Jacobs, A. von Stechow, W. Sternefeld, and T. Vennemann (eds), 506-569. Berlin: Walter de Gruyter.

Chomsky, N. 2000. Minimalist inquiries: The framework. In Step by step, R. Martin,D. Michaels, and J. Uriagereka (eds), 89-156. Cambridge, MA: MIT Press.

Chomsky, N. 2001. Derivation by phase. In Ken Hale: A life in language, M. Kenstowicz (ed.), 152. Cambridge, MA: MIT Press.

Chomsky, N. 2004. Beyond explanatory adequacy. In The cartography of syntactic structures, volume 3: Structures and beyond, A. Belletti (ed.), 104-131. Oxford: Oxford University Press.

Christensen, K. K. 1986. Norwegian ingen: A Case of Post-Syntactic Lexicalization. In Scandinavian syntax, Ö. Dahl and A. Holmberg (eds), 21-35. Institute of Linguistics, University of Stockholm.

Clark, R., and I. Roberts. 1993. A computational approach to language learnability and language change. Linguistic Inquiry 24:299-345.

Danchev, A. 1991. Language change typology and some aspects of the SVO developmentin English. In Historical English syntax, D. Kastovsky (ed.), 103-124. Berlin \& New York: Mouton de Gruyter.

Dehé, N. 2001. Particle verbs in English: Syntax, information structure, and intonation. Amsterdam: Benjamins.

Den Dikken, M. 1995. Particles. Oxford: Oxford University Press.

Diderichsen, P. 1946. Elementær dansk grammatik. Gyldendal, København.

Dryer, M. S. 1992. The Greenbergian word order correlations. Language 68:81-138.

Emonds, J. 1987. The Invisible Category Principle. Linguistic Inquiry 18:613-632.

Emonds, J. 2006. Syntactic conditions on phonetically empty morphemes. In Organizing grammar: Linguistic studies in honor of Henk van Riemsdijk, H. Broekhuis, N. Corver, R. Huybregts, U. Kleinhenz and J. Koster (eds), 111-121. Berlin: Mouton de Gruyter.

Evers, A. 1975. The transformational cycle in Dutch and German. University of Utrecht dissertation. 
Fischer, 0.1989. The origin and spread of the accusative and infinitive construction in English. Folia Linguistica Historica 8:143-217.

Fischer, 0. 2006. Morphosyntactic change: Functional and formal perspectives. Oxford: Oxford University Press.

Fischer, 0., A. van Kemenade, W. Koopman, and W. van der Wurff. 2000. The syntax of early English. Cambridge: CUP.

Fuss, E., and C. Trips. 2002. Variation and change in Old and Middle English: On the validity of the Double Base Hypothesis. The Journal of Comparative Germanic Linguistics 4:171-224.

Grace, E. Jr. 1971. The order of constituents in Indo-European. Austin: University of Texas, dissertation.

Halle, M. and A. Marantz. 1993. Distributed Morphology and the pieces of inflection. In The view from Building 20, K. Hale and S. J. Keyser (eds), 111-176. Cambridge MA: MIT Press.

Hawkins, J. 1983. Word order universals. New York: Academic Press.

Hock, H. H. 1986. Principles of historical linguistics. Berlin: Mouton de Gruyter.

Holmberg, A. 2000. Deriving OV order in Finnish. In The derivation of VO and OV, P. Svenonius (ed.), 123-152. Amsterdam: Benjamins.

Johnson, K. 1991. Object positions. Natural Language and Linguistic Theory 9:577-636.

Jónsson, J. G. 1996. Clausal architecture and case in Icelandic. University of Massachusetts at Amherst dissertation.

Kemenade, A. van. 1984. Verb second and clitics in Old English. In Linguistic in the Netherlands, H. Bennis and W.U.S. van Lessen Kloeke (eds), 101-110. Dordrecht: Foris.

Kemenade, A. van. 1987. Syntactic case and morphological case in the history of English. Dordrecht: Foris.

Kemenade, A. van. 1991/1993. Verbal position in Old English: Evidential problems. Studia Anglica Posnaniensia XXV-XXVII:81-94.

Kemenade, A. van. 1993. The history of English modals: A reanalysis. Folia Linguistica Historica 13:143-166.

Kemenade, A. van. 2007. Subdevelopments in the loss of OV word order in the history of English. Handout from the talk at the CASTL Colloquium, 20 September 2007.

Kiparsky, P. 1996. The shift to head-initial VP in Germanic. In Studies in Comparative Germanic Syntax: Volume II, H. Thráinsson, S. D. Epstein, and S. Peter (eds), 140-179. Dordrecht: Kluwer. 
Koopman, W. F. 1990. The double object construction in Old English. In Papers from the $5^{\text {th }}$ International Conference on English Historical Linguistics, S. M. Adamson, V. A. Law, N. Vincent, and S. Wright (eds), 225-243. Amsterdam/Philadelphia: John Benjamins Publishing Company.

Koopman, W. F. 1991-1993. The order of dative and accusative objects in Old English and scrambling. Studia Anglica Posnaniensia XXV-XXVII:109-121.

Koopman, W. F. 1992. Old English clitic pronouns: Some remarks. In Evidence for Old English: Material and Theoretical Bases for Reconstruction, F. Colman (ed.), 44-87. Edinburgh: John Donald Publishers.

Koopman, W. F. 1997. Another look at clitics in Old English. Transactions of the Philological Society 95:73-93.

Koster, J. 1975. Dutch as an SOV Language. Linguistic Analysis 1:111-136.

Kroch A. S., and A. Taylor. 1997. Verb movement in Old and Middle English: Dialect variation and language contact. In Parameters of Morphosyntactic Change, A. van Kemenade and N. Vincent (eds), 297-325. Cambridge: Cambridge University Press.

Kroch, A. S. 1989. Reflexes of grammar in patterns of language change. Language Variation and Change 1:199-244.

Kroch, A. S., and A. Taylor. 2000. Verb-object order in early Middle English. In Diachronic syntax: Models and mechanisms, S. Pintzuk, G. Tsoulas and A. Warner (eds), 132-163. Oxford: Oxford University Press.

Kuhn, H. 1933. Zur Wortstellung und Betonung im Alt-Germanischen. Paul und Braune's Beiträge 57.1-109.

Lamontagne, G. and L. Travis. 1987. The syntax of adjacency. In Proceedings of WCCFL 6, M. Crowhurst (ed.), 173-186. Stanford: CSLI Publications.

Lasnik, H. 2003. Minimalist investigations in linguistic theory. London: Routledge.

Lehmann, W. P. 1973. A structural principle of language and its implications. Language 49:4766.

Lehnert, M. 1957. The interrelation between form and function in the development of the English language. Zeitschrift für Anglistik und Amerikanistik 5:43-56.

Lightfoot, D. 1979. Principles of diachronic syntax. Cambridge: Cambridge University Press.

Lightfoot, D. 1991. How to set parameters: Arguments from language change. Cambridge, MA: MIT Press.

Marantz, A. 1991. Case and licensing. In Proceedings of ESCOL'91, G. F. Westphal, B. Ao and H.-R. Chae (eds), 234-253. Cornell Linguistics Club. 
Marchand, H. 1951. The syntactical change from inflectional to word order system and some effects of this change on the relation 'verb/object' in English: A diachronic-synchronic interpretation. Anglia 70:70-89.

McCarthy, J. and A. Prince. 1993. Generalized alignment. In Yearbook of Morphology 1993, G. Booij and J. van Marle (eds), 79-153. Dordrecht: Kluwer.

McFadden, T. 2004. The position of morphological case in the derivation: A study on the syntaxmorphology interface. University of Pennsylvania dissertation.

McFadden, T. 2005. OV-VO in English and the role of case-marking in word order. English Language and Linguistics 9.1:63-82.

Miller, G. D. 2002. Nonfinite structures in theory and change. Oxford: Oxford University Press.

Moerenhout, M., and W. van der Wurff. 2000. Remnants of the old order: OV in the Paston Letters. English Studies 81:513-530.

Neeleman, A. 1994. Complex predicates. Utrecht University dissertation/LOT Dissertation series.

Neeleman, A. 2002. Particle placement. In Verb-particle explorations, N. Dehé (ed.), 141-164. Berlin: Mouton de Gruyter.

Neeleman, A. and T. Reinhart. 1998. Scrambling at the PF interface. In The projection of arguments, M. Butt and W. Gueder (eds), 309-353. Stanford: CSLI Publications.

Neeleman, A., and F. Weerman. 1999. Flexible syntax: A theory of case and arguments. Dordrecht: Kluwer.

Pintzuk, S., and A. Taylor. 2006. The loss of OV order in the history of English. In The Handbook of the History of English, A. van Kemenade and B. Los (eds), 249-278. Oxford: Blackwell Publishing.

Pintzuk, S. 1991. Phrase structures in competition: variation and change in Old English word order. University of Pennsylvania dissertation.

Pintzuk, S. 1999. Phrase structures in competition. New York \& London: Garland.

Pintzuk, S. 2002. Verb-object order in Old English: Variation as grammatical competition. In Syntactic effects of morphological change, D. Lightfoot (ed.), 276-299. Oxford: Oxford University Press.

Pintzuk, S. 2005. Arguments against a universal base: evidence from Old English. English Language and Linguistics 9.1:115-138.

Rizzi, L. 1990. Relativized minimality. Cambridge, MA: MIT Press.

Roberts, I., and A. Roussou. 2003. Syntactic change: A minimalist approach to grammaticalization. Cambridge: Cambridge University Press. 
Roberts, I. 1997. Directionality and word order change in the history of English. In Parameters of morphosyntactic change, A. van Kemenade and N. Vincent (eds), 397-426. Cambridge: Cambridge University Press.

Roeper, T., and S. J. Keyser. 1992. Re: the abstract clitic hypothesis. Linguistic Inquiry 23:89125.

Rutten, J. 1991. Infinitival complements and auxiliaries. University of Amsterdam dissertation.

Santorini, B. 1989. The generalization of the Verb Second constraint in the history of Yiddish. University of Pennsylvania dissertation.

Santorini, B. 1992. Variation and change in Yiddish subordinate clause word order. Natural Language and Linguistic Theory 10:595-640.

Santorini, B. 1993. The rate of phrase structure change in the history of Yiddish.Language Variation and Change 5:257-283.

Sapir, E. 1921. Language. New York: Hartcourt Brace Jovanovich.

Selkirk, E. 1986. On derived domains in sentence phonology. Phonology Yearbook 3:371-405.

Selkirk, E. 1995. The prosodic structure of function words. In University of Massachusetts Occasional Papers 18: Papers in Optimality Theory, 439-469. University of Massachusetts, Amherst: GLSA.

Smith, J. R. 1971. Word order in the older Germanic dialects. Urbana-Champaign: University of Illinois dissertation.

Stockwell, R. P. 1977. Motivations for exbraciation in Old English. In Mechanisms of syntactic change, C. Li (ed.), 291-314. Austin: University of Texas Press.

Stockwell, R. P., and D. Minkova. 1991. Subordination and word order change in the history of English. In Historical English syntax, D. Kastovsky (ed.), 367-408. Berlin \& New York: Mouton de Gruyter.

Stowell, T. 1981. Origins of phrase structure. MIT dissertation.

Sundquist, J. D. 2002. Morphosyntactic change in the history of the Mainland Scandinavian languages. Indiana University dissertation.

Temürcü, C. 2001. Word order variations in Turkish: Evidence from binding and scope. MA thesis, the Middle East Technical University.

Thiersch, C. 1978. Topics in German syntax. Cambridge, MA: MIT dissertation.

Thráinsson, H. 2007. The syntax of Icelandic. Cambridge: Cambridge University Press.

Tokizaki, H., and Y. Kuwana. 2008. Non-existent word orders and left-branching structure. Paper presented at GLOW, Newcastle-upon-Tyne. 
Trnka, B. 1928. Analysis and synthesis in English. English Studies 10:138-144.

Truckenbrodt, H. 1995. Phonological phrases: Their relation to syntax, focus, and prominence. Cambridge, MA: MIT dissertation.

Truckenbrodt, H. 1999. On the relation between syntactic phrases and phonological phrases. Linguistic Inquiry 30:219-255.

Vennemann, T. 1974. Topics, subjects, and word order: From SXV to SVX via TVX. In Historical linguistics: Proceedings of the First International Congress of Historical Linguistics. Edinburgh, September 1973, vol. II, J. Anderson and C. Jones (eds), 339-376. Amsterdam: North-Holland.

Vinokurova, N. 2007. On the impossibility of agent-denoting gerunds in Sakha. Handout from ST@R meeting.

Wackernagel, J. 1892. Über ein Gesetz der indogermanischen Wortstellung. Indogermanische Forschungen 1:333-436.

Wagner, M. 2005. Prosody and recursion. MIT dissertation.

Warner, A. 1982. Complementation in Middle English and the methodology of historical syntax. University Park and London: The Pennsylvania State University Press.

Weerman, F. 1987. The change from OV to VO as a possible change. In Linguistics in the Netherlands, F. Beukema and P. Coopmans (eds), 223-232. Dordrecht: Foris.

Wiland, B. 2009. Aspects of order preservation in Polish and English. Doctoral dissertation, University of Poznań.

Wurff, W. van der, and T. Foster. 1997. Object-verb order in 16th century English: A study of its frequency and status. In Language History and Linguistic Modelling, Vol. I, R. Hickey and S. Puppel (eds), 439-453. Berlin: Mouton de Gruyter.

Wurff, W. van der. 1997. Deriving object-verb order in late Middle English. Journal of Linguistics 33:485-509.

Wurff, W. van der. 1999. Objects and verbs in modern Icelandic and fifteenth-century English: A word order parallel and its causes. Lingua 109:237-65.

Zec, D. and S. Inkelas. 1990. Prosodically constrained syntax. In The phonology-syntax connection, D. Zec and S. Inkelas (eds), 365-378. Chicago: University of Chicago Press.

Zeller, J. 2001. Particle verbs and local domains. Amsterdam: John Benjamins. 